\title{
Radon activity in the lower troposphere and its impact on ionization rate: a global estimate using different radon emissions
}

\author{
K. Zhang ${ }^{1, *}$, J. Feichter ${ }^{1}$, J. Kazil ${ }^{2,9}$, H. Wan ${ }^{1}$, W. Zhuo ${ }^{3}$, A. D. Griffiths ${ }^{4}$, H. Sartorius ${ }^{5}$, W. Zahorowski ${ }^{4}$, \\ M. Ramonet ${ }^{6}$, M. Schmidt ${ }^{6}$, C. Yver $^{6}$, R. E. M. Neubert ${ }^{7}$, and E.-G. Brunke ${ }^{8}$ \\ ${ }^{1}$ Max Planck Institute for Meteorology, Hamburg, Germany \\ ${ }^{2}$ Cooperative Institute for Research in Environmental Sciences (CIRES), University of Colorado, Boulder, Colorado, USA \\ ${ }^{3}$ Institute of Radiation Medicine, Fudan University, Shanghai, China \\ ${ }^{4}$ Australian Nuclear Science and Technology Organisation, Lucas Heights NSW 2234, Australia \\ ${ }^{5}$ Federal Office for Radiation Protection (BfS), Salzgitter, Germany \\ ${ }^{6}$ Laboratoire des Sciences du Climat et de l'Environnement, IPSL, CEA, UVSQ, CNRS, Gif-sur-Yvette, France \\ ${ }^{7}$ Centre for Isotope Research, University of Groningen, Groningen, The Netherlands \\ ${ }^{8}$ South African Weather Service, Stellenbosch, South Africa \\ ${ }^{9}$ NOAA Earth System Research Laboratory (ESRL), Boulder, Colorado, USA \\ *now at: Pacific Northwest National Laboratory, Richland, Washington, USA
}

Received: 16 October 2010 - Published in Atmos. Chem. Phys. Discuss.: 28 January 2011

Revised: 15 July 2011 - Accepted: 1 August 2011 - Published: 3 August 2011

\begin{abstract}
The radioactive decay of radon and its progeny can lead to ionization of air molecules and consequently influence aerosol size distribution. In order to provide a global estimate of the radon-related ionization rate, we use the global atmospheric model ECHAM5 to simulate transport and decay processes of the radioactive tracers. A global radon emission map is put together using regional fluxes reported recently in the literature. Near-surface radon concentrations simulated with this new map compare well with measurements.

Radon-related ionization rate is calculated and compared to that caused by cosmic rays. The contribution of radon and its progeny clearly exceeds that of the cosmic rays in the midand low-latitude land areas in the surface layer. During cold seasons, at locations where high concentration of sulfuric acid gas and low temperature provide potentially favorable conditions for nucleation, the coexistence of high ionization rate may help enhance the particle formation processes. This suggests that it is probably worth investigating the impact of radon-induced ionization on aerosol-climate interaction in global models.
\end{abstract}

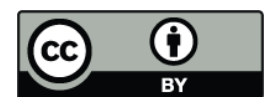

Correspondence to: $\mathrm{K}$. Zhang

(kai.zhang@pnnl.gov)

\section{Introduction}

In recent years the impact of atmospheric ions on aerosol formation and life cycle has attracted increasing attention (see, e.g., Yu and Turco, 2000; Lovejoy et al., 2004; Kulmala et al., 2004; Kazil et al., 2006, among others). Atmospheric ions can enhance the production of ultrafine aerosol particles because they greatly stabilize small clusters against evaporation (Ramamurthi et al., 1993; Lovejoy et al., 2004). In addition, ions can attach to existing aerosol particles (either neutral or charged), change their charge status, and thus the coagulation rates (Clement and Harrison, 1992). Through influence on aerosol number and size distribution, ions can eventually exert an impact on the Earth's climate. Kazil et al. (2010) show that in the global aerosol-climate model ECHAM5-HAM, charged $\mathrm{H}_{2} \mathrm{SO}_{4} / \mathrm{H}_{2} \mathrm{O}$ nucleation induces a $-1.15 \mathrm{~W} \mathrm{~m}^{-2}$ (global and annual mean) flux of shortwave radiation at the top of the atmosphere via direct, semi-direct and indirect aerosol effects. This value is considerably larger than the fluxes caused by cluster activation $\left(-0.235 \mathrm{~W} \mathrm{~m}^{-2}\right)$ and neutral $\mathrm{H}_{2} \mathrm{SO}_{4} / \mathrm{H}_{2} \mathrm{O}$ nucleation $\left(-0.05 \mathrm{~W} \mathrm{~m}^{-2}\right)$. In that work only the galactic cosmic rays are considered when computing the ionization rate. Although galactic cosmic rays play a major role in the upper troposphere and lower stratosphere, over the oceans and in the polar regions, other natural processes also cause ionization, the main contributors being the radioactive decay of radon $\left({ }^{222} \mathrm{Rn}\right)$, thoron $\left({ }^{220} \mathrm{Rn}\right)$ and

Published by Copernicus Publications on behalf of the European Geosciences Union. 
(a)

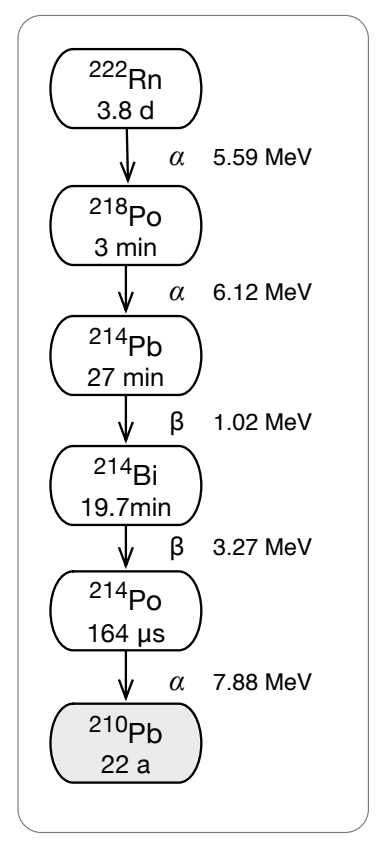

(b)

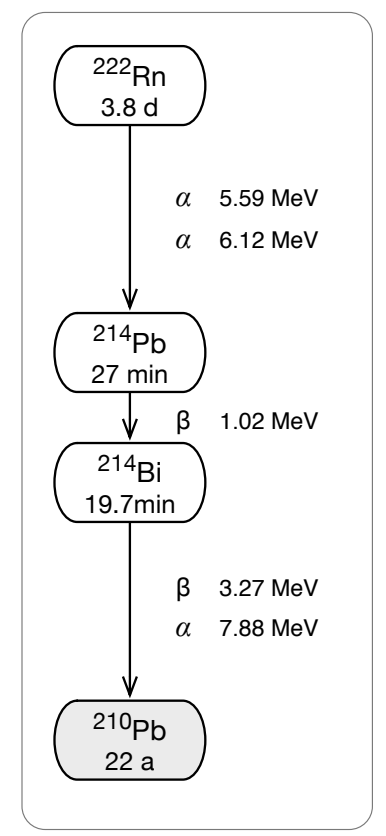

Fig. 1. (a) Radioactive decay of radon and its progeny. The halflife, decay type and decay energy of each species are also listed. (b) The simplified decay chain considered in our simulations.

their progeny, as well as terrestrial gamma radiation (Harrison and Carslaw, 2003). Near the land surface, almost half of the ionization of the air is related to radon, thoron and their daughter products (Emsley, 2001).

Radon, the decay product of ${ }^{226} \mathrm{Ra}$, is the most prominent natural radionuclide in the surface air. It is a noble gas with very low solubility in water. After being transpired into the air, radon can be redistributed into the middle and upper troposphere and over synoptic distance in the horizontal, due to its half-life of 3.8 days. The radioactive decay of ${ }^{222} \mathrm{Rn}$ and its progeny produces highly energetic $\alpha$ and $\beta$ particles which ionize air molecules (Fig. 1a). A previous laboratory study by Vohra et al. (1984) showed that under typical nearsurface conditions over land, ionization caused by radioactive decay of radon series can cause significant enhancements in particle formation. To find out whether it is necessary to consider radon-related nucleation in global aerosol models, we use the global climate model ECHAM5 to compare the radon-related ionization rate with that caused by cosmic rays.

In order to obtain a realistic estimate of radon-related ionization rate, one needs sufficiently accurate information about radon emission flux on the global scale, as well as a numerical model that reasonably represents radon-related transport and decay processes. To this end a new global emission map is compiled in this study, and the transport processes in the ECHAM5 model are evaluated. The details are presented in Sects. 2 and 3. The simulated radon-related ionization rate is discussed in Sect. 4. Conclusions are drawn in Sect. 5.

\section{Model, emission data, and simulations}

In this section we first explain why we only choose radon and its progeny as ionization agents in this study. Thereafter the newly derived global radon emission map is presented (Sect. 2.2). We then briefly introduce the ECHAM5 model (Sect. 2.3) and document how radioactive decay and the resulting ionization are implemented in the model (Sects. 2.4, 2.5, and 2.6). The numerical simulations are introduced in Sect. 2.7 .

\subsection{Ionization agents}

Since our primary interest lies in climate modelling on the global scale, the focus of this study was chosen by two criteria: first, the source of ionizing energy has to be strong enough to cause a globally non-negligible effect; Second, sufficient information needs to be available about the global distribution of the radionuclide and its sources, so that robust results can be obtained with our climate model. According to these criteria, we have chosen the radon decay series as the subject in this study.

Here we have deliberately excluded other well-known radionuclides for various reasons. For example, ${ }^{85} \mathrm{Kr}$ has a long lifetime and fairly homogeneous background concentration worldwide, which makes it a continuous source of ionization. Over the ocean, its activity concentration can exceed that of radon. However, the decay energy of ${ }^{85} \mathrm{Kr}$ is relatively low (mainly $\beta$ decay, average energy $0.251 \mathrm{MeV}$ ), and the activity concentration near land surface is much lower than radon. The resulting ionization in the lower troposphere is thus probably negligible compared to radon and cosmic rays. Similarly, ionization caused by ${ }^{14} \mathrm{C}$ in $\mathrm{CO}_{2}$ is neglected due to its low decay energy $(0.156 \mathrm{MeV})$ and low activity concentration $\left(40 \mathrm{mBq} \mathrm{m}^{-3}\right)$. The thoron decay chain could have been another potential subject for our study. Although thoron $\left({ }^{220} \mathrm{Rn}\right)$ and its direct daughter ${ }^{216} \mathrm{Po}$ undergo essentially complete decay below an altitude of several meters over land (with half-lives being $56 \mathrm{~s}$ and $0.15 \mathrm{~s}$, respectively), the next decay product, ${ }^{212} \mathrm{~Pb}$, has a half-life of $10.6 \mathrm{~h}$. However, it should be noted that the activity concentration of ${ }^{212} \mathrm{~Pb}$ is only about $1 \%-10 \%$ of that of radon. Moreover, there exists the practical difficulty that information about thoron emission is very limited. To our knowledge there is no global map available, which prevents us from obtaining reliable distributions of thoron and its progeny. Given all the considerations above, we focus only on the radon-induced ionization in this study.

\subsection{Radon emission}

Early studies have shown that the average continental radon emission flux ranges from 0.7 to 1.2 atom $\mathrm{cm}^{-2} \mathrm{~s}^{-1}$ (Turekian et al., 1977; Lambert et al., 1982). Based on this estimate, highly simplified emission fluxes have been used 


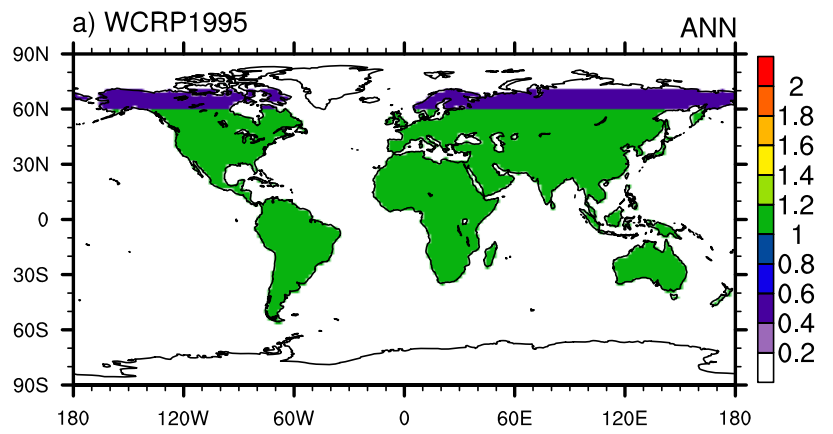

b) SW1998 scaled
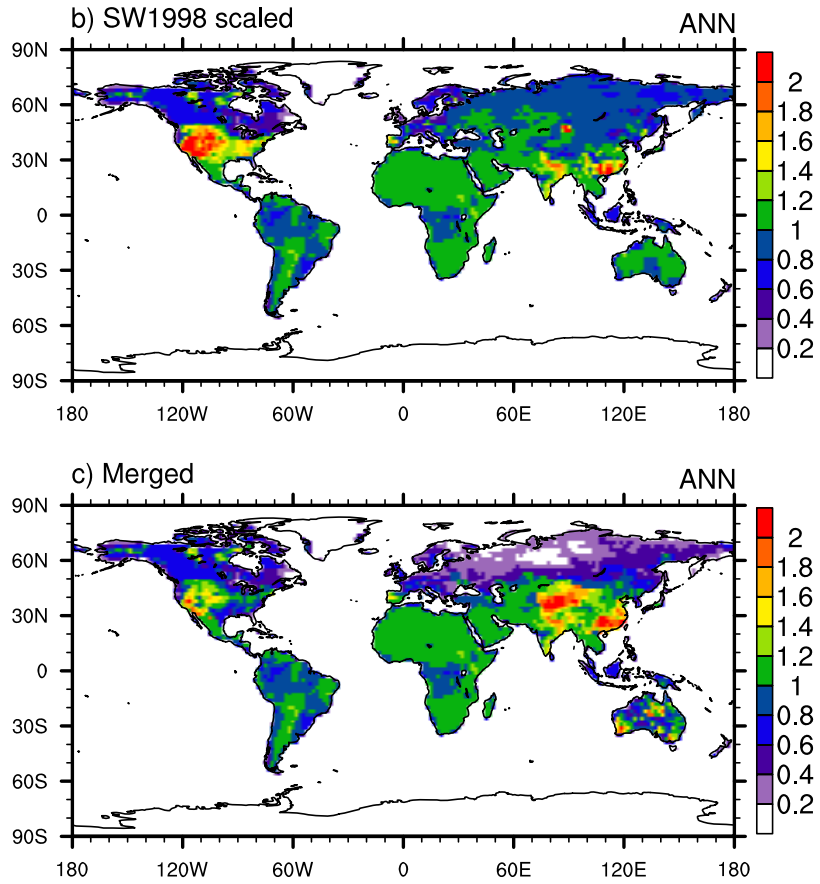

d) Data source of the merged map

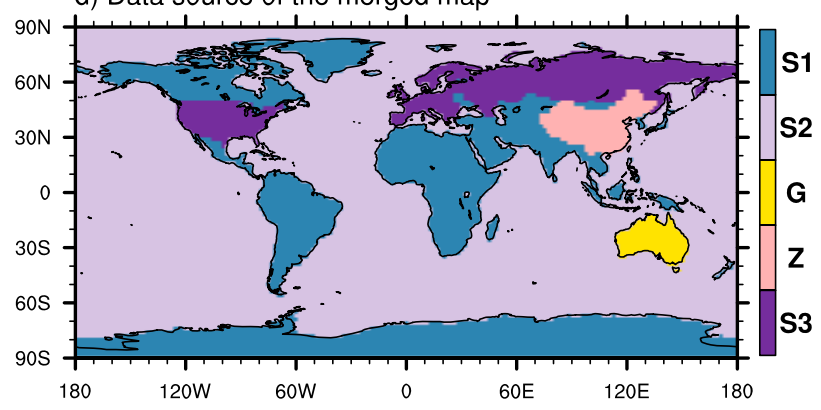

Fig. 2. (a-c) Radon emission setups considered in this study. The quantity shown is the annual mean atom number flux (unit: atom $\mathrm{cm}^{-2} \mathrm{~s}^{-1}$ ). (d) Data source of the merged emission map shown in (c). S1 stands for Schery and Wasiolek (1998) (scaled), S2 for Schery and Huang (2004), G for Griffiths et al. (2010), Z for Zhuo et al. (2008), and S3 for Szegvary et al. (2007).
Table 1. Regionally averaged annual mean radon emission flux over land in the merged radon flux map.

\begin{tabular}{lc}
\hline Region & $\begin{array}{c}\text { Emission Flux } \\
\text { (atom cm }\end{array} \mathrm{s}^{-1}$ ) \\
\hline Europe & 0.62 \\
China & 1.41 \\
Russia & 0.39 \\
USA & 0.87 \\
Australia & 1.02 \\
Others & 0.92 \\
Global (between $60^{\circ} \mathrm{S}$ and $60^{\circ} \mathrm{N}$ ) & 0.96 \\
\hline
\end{tabular}

in model intercomparison studies. For example, the World Climate Research Program (WCRP) Cambridge Workshop of 1995 (Rasch et al., 2000) specified a uniform continental emission of 1 atom $\mathrm{cm}^{-2} \mathrm{~s}^{-1}$ between $60^{\circ} \mathrm{S}$ and $60^{\circ} \mathrm{N}, 0.5$ atom $\mathrm{cm}^{-2} \mathrm{~s}^{-1}$ between $60^{\circ} \mathrm{N}$ and $70^{\circ} \mathrm{N}$ (excluding Greenland), and zero flux elsewhere. On the other hand, Lee and Feichter (1995) and Guelle et al. (1998) showed that taking into account regional gradient can lead to results more consistent with the observed radon concentrations, especially near the surface and at high latitudes. Conen and Robertson (2002) proposed a northward decreasing source (linear decrease from 1 atom $\mathrm{cm}^{-2} \mathrm{~s}^{-1}$ at $30^{\circ} \mathrm{N}$ to 0.2 atom $\mathrm{cm}^{-2} \mathrm{~s}^{-1}$ at $70^{\circ} \mathrm{N}$ ) without zonal gradient. This emission assumption was tested with a global transport model by Robertson et al. (2005). Before our work presented in this paper, the global radon flux map by Schery and Wasiolek (1998) (hereafter SW1998) was the only one that includes detailed regional information and seasonal variation over land surfaces. It has been used in several studies of transport modelling (see, e.g., Koch et al., 2006; Hirao et al., 2008). (Goto et al. (2008) showed limited results from a radon exhalation rate distribution model, but without comprehensive evaluation.) One of the weak points of the SW1998 map is the lack of overall normalization. The annual and global mean emission rate over land $\left(1.6\right.$ atom $\left.\mathrm{cm}^{-2} \mathrm{~s}^{-1}\right)$ is higher than that given by many previous estimates (Schery and Wasiolek, 1998; Schery, 2004). Thus it is suggested (Schery 2009, personal communication) that one could let the overall normalization be a free parameter. For example, Koch et al. (2006) arbitrarily reduced the emission by a factor of 0.5 in their work.

In the past years several research groups have derived detailed radon flux maps for different regions using various methods. For example, Szegvary et al. (2007) and Szegvary et al. (2009) established a method for deriving radon emission from terrestrial gamma dose rate. The radon fluxes they obtained are in good agreement with in situ measurements in Finland and Hungary. Their flux map was applied in the TM5 atmospheric tracer model and improved the average model predictions (Szegvary, 2007). Flux maps of Russia and USA are now available from their website at http://radon.unibas.ch 


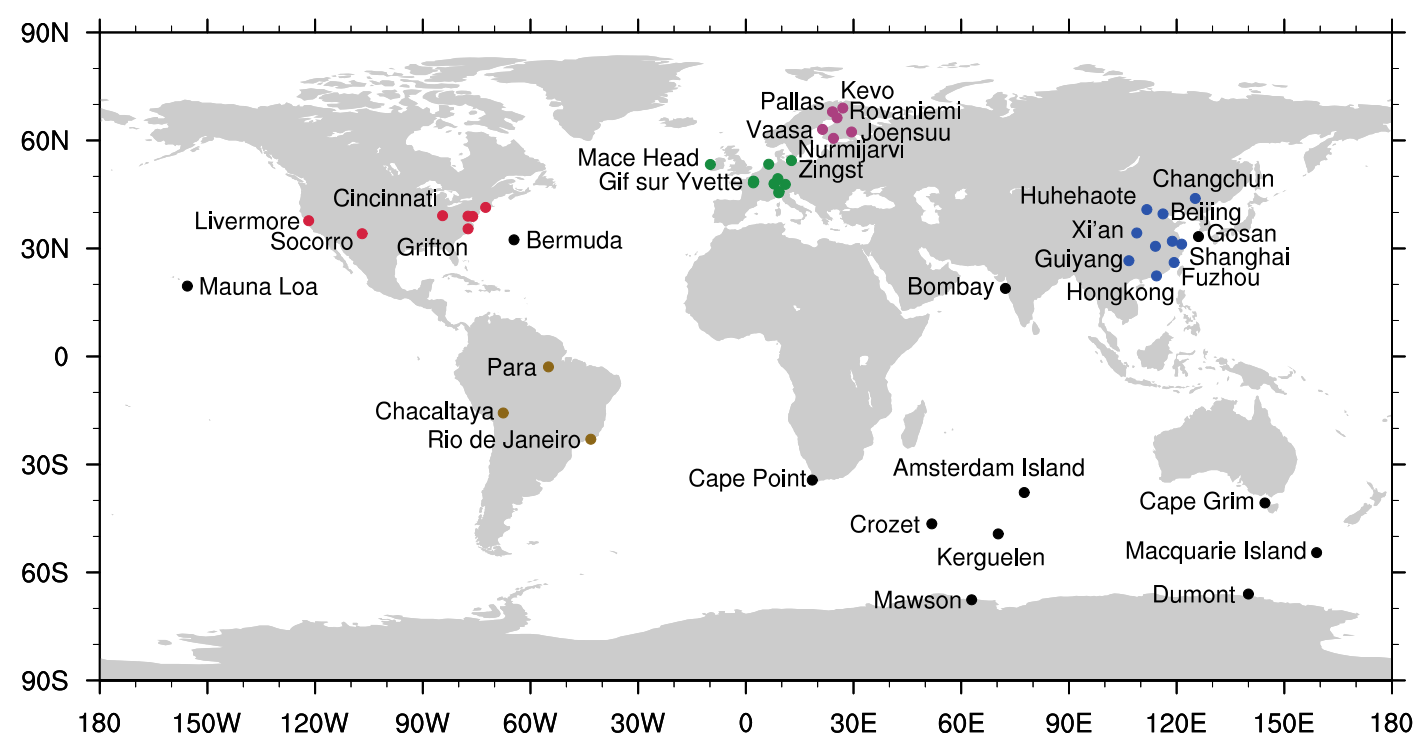

Fig. 3. Location of surface radon measurements used in this study. See Table 2 for further information of the sites. Colors indicate observational sites in the five different regions that are analysed separately in Fig. 5.

as well. Zhuo et al. (2008) published radon emission estimates for China based on the soil ${ }^{226} \mathrm{Ra}$ content and a global ecosystems database. The annual mean values given by their idealized model range from 0.5 to 2.7 atom $\mathrm{cm}^{-2} \mathrm{~s}^{-1}$ at different locations. Furthermore, Griffiths et al. (2010) reported a time-dependent map of radon flux density at high resolutions for Australia. For the oceans, Schery and Huang (2004) calculated radon flux from the surface wind speed and sea water ${ }^{226}$ Ra content using a gas transfer model.

Based on the studies mentioned above, we compile a new global radon emission map in this work (Fig. 2). The new map uses the Szegvary et al. (2007) data for Europe, Russia and USA, Zhuo et al. (2008) for China, Griffiths et al. (2010) for Australia (pre-release), and the Schery and Wasiolek (1998) map for other land areas but scaled by a factor of $\frac{1}{1.6}$. The Schery and Huang (2004) estimates are used for the oceans. Table 1 shows the annual mean regionally averaged radon emission flux over land in this merged map. For intercomparison, simulations are performed using this merged map, the WCRP1995 recommendation, and the scaled (also by a factor of $\frac{1}{1.6}$ ) SW1998 map. The decision of using $\frac{1}{1.6}$ for the normalization instead of 2 as in Koch et al. (2006) is somewhat arbitrary. The idea is that $\frac{1}{1.6}$ results in a landsurface mean of 1 atom $\mathrm{cm}^{-2} \mathrm{~s}^{-1}$, which is the value used for middle and low latitudes in the WCRP1995 protocol. On the other hand, we do not make it a strict rule that all three simulations must have the same global mean emission.

\subsection{The climate model ECHAM5}

ECHAM5 (Roeckner et al., 2003) is an atmospheric general circulation model developed at the Max Planck Institute for
Meteorology. Its spectral transform dynamical core solves the primitive equations in vorticity-divergence form. The horizontal resolution used in this study is T63, which applies a triangular truncation to the spherical harmonic series, and resolves horizontal patterns up to wave number 63 . The corresponding Gaussian grid, on which the grid-point computations including physics parameterizations are performed, has approximately $2^{\circ}$ (latitude) $\times 2^{\circ}$ (longitude) grid size. In the vertical, the model domain is unevenly divided into 31 layers in pressure-based terrain following coordinate, with the highest computational level located at $10 \mathrm{hPa}$. Roughly speaking, there are 6 layers below $850 \mathrm{hPa}, 9$ above $200 \mathrm{hPa}$, and 16 in between. The standard time step for this model resolution is $12 \mathrm{~min}$.

The large-scale advection of tracer species is handled by the Lin and Rood (1996) flux-form semi-Lagrangian algorithm, assuming piecewise parabolic sub-grid distribution. Within the physics parameterization package, the turbulent surface fluxes are calculated from the Monin-Obukhov similarity theory (Louis, 1979). Vertical diffusion coefficients are calculated as functions of turbulent kinetic energy (Brinkop and Roeckner, 1995). The parameterization of cumulus convection and convective transport of tracer is based on the bulk mass flux concept of Tiedtke (1989), with further modifications by Nordeng (1994).

\subsection{Decay of the radon family in the model}

The decay chain of radon is shown in Fig. 1a. Half-lifes and the $\alpha$ decay energy noted therein are collected from the most recent Evaluated Nuclear Structure Data File (ENSDF). Among the decay products, ${ }^{218} \mathrm{Po}$ and ${ }^{214} \mathrm{Po}$ have half-lifes 
Table 2. Detailed information about the surface radon measurements used in this study. In the "Reference" column, DWD stands for Deutscher Wetterdienst (German Weather Service), BfS for Federal Office for Radiation Protection of Germany, IPSL for Institut PierreSimon Laplace, EML for DOE/Environmental Measurements Laboratory, and NCAR/EOL for National Center for Atmospheric Research Earth Observing Laboratory. The right most column categorizes the data source: I: Data already used for model evaluation in Zhang et al. (2008); II: Data of the period 1955-1987 compiled by J. Feichter; III: New measurements from observers; IV: New data from recent publications. Location of these site are also shown in Fig. 3.

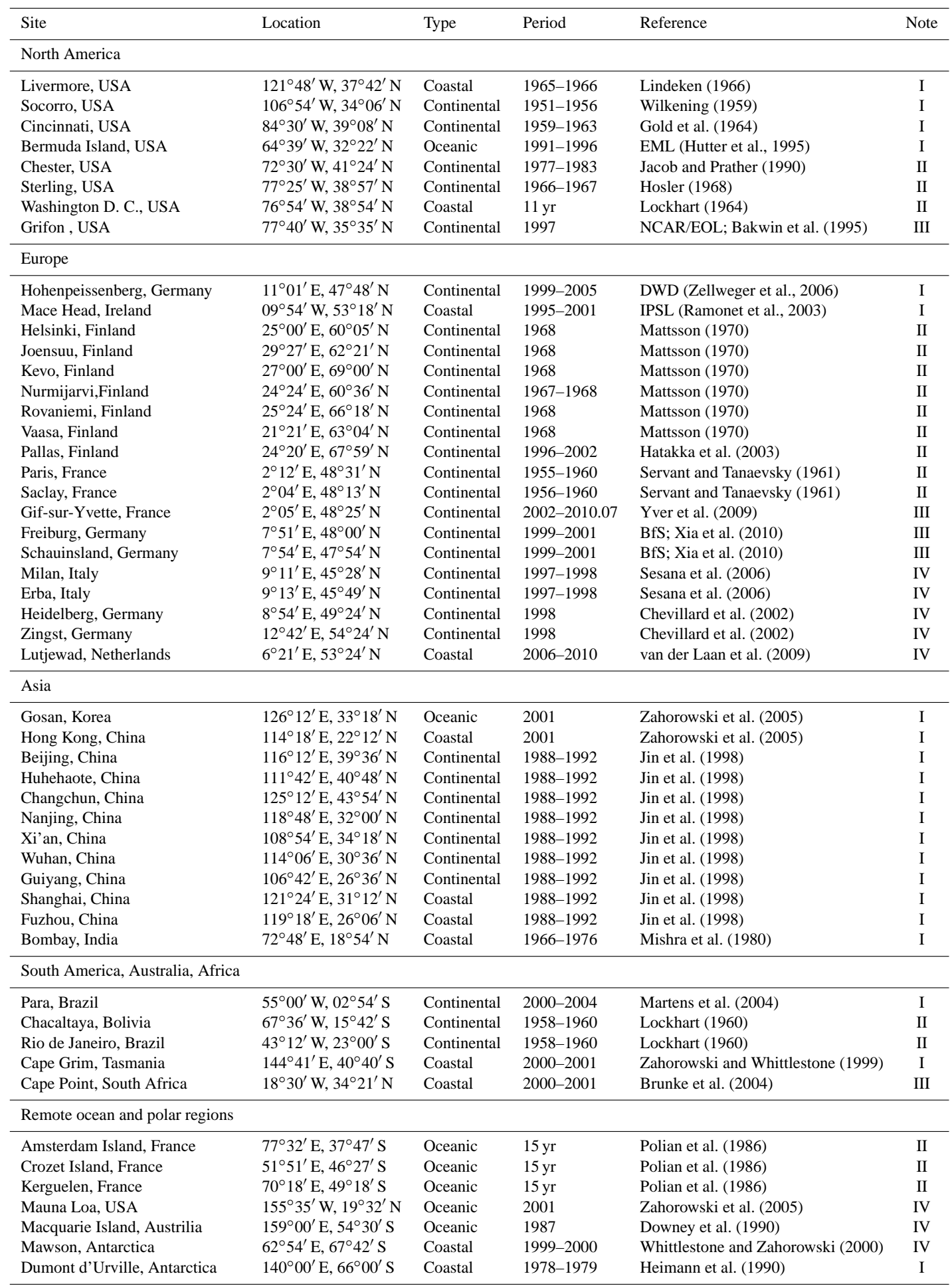


much shorter than the time step of the climate model, thus ignored as intermediate products. We assume ${ }^{222} \mathrm{Rn}$ decays directly to ${ }^{214} \mathrm{~Pb}$ and releases two $\alpha$ particles with $11.71 \mathrm{MeV}$ decay energy (Fig. 1b). Similarly, ${ }^{214} \mathrm{~Pb}$ decays directly into ${ }^{210} \mathrm{~Pb}$ and releases one $\alpha$ particle and one $\beta$ particle, emitting $11.15 \mathrm{MeV}$ energy. The decay of ${ }^{210} \mathrm{~Pb}$ is ignored because it happens very slowly (mostly not in the atmosphere but on the ground) and produces negligible energy $(0.064 \mathrm{MeV})$. In this study we describe the abundance of radon and its progeny by the activity concentration which is the product of atom number concentration and decay constant. The simplified decay chain can be described by an ordinary differential equation system and solved analytically (cf., e.g., Vinuesa et al., 2007) within each model time step (cf. Appendix A).

In the real atmosphere, radon decay initiates ion chemical reactions which can lead to the formation of nanometersized charged clusters. Radon decay products can also attach to existing particles (Porstendörfer, 1994; Papastefanou, 2008). Both the unattached and attached radon decay products are subject to dry and wet scavenging. Near the ground, dry deposition of these decay products may play a role under certain conditions. However, Lupu and Cuculeanu (1999) showed that even above vegetated ground (where the dry deposition velocity is supposed to be larger than above bare ground), the effect of dry deposition on the concentration of radon decay products above $5 \mathrm{~m}$ is relatively small compared to the effect of turbulent mixing. Considering these results and the fact that scavenging happens at time scales much longer than the life-times of the progeny, we ignore this process in our simulations.

\subsection{Ionization}

The production of one ion pair in the air consumes 35-36 eV energy from $\alpha$ particles (Valentine and Curran, 1958; Jesse, 1968; Papastefanou, 2008), or $32-34 \mathrm{eV}$ from $\beta$ particles (Jesse, 1968; Papastefanou, 2008). In this study, we use the value $35.6 \mathrm{eV}$ for $\alpha$ particles and $32.5 \mathrm{eV}$ for $\beta$ particles (Papastefanou, 2008). Using these numbers and the decay energy noted in Fig. 1b, the time step mean ionization rate $\psi$ (unit: $\mathrm{cm}^{-3} \mathrm{~s}^{-1}$ ) is diagnosed by

$\psi_{i}=\bar{c}_{i}\left(n_{\alpha} \frac{E_{\alpha, i}}{E_{\alpha, p}}+n_{\beta} \frac{E_{\beta, i}}{E_{\beta, p}}\right), \quad i=1,2,3$

Here $\bar{c}_{i}$ stands for the time step mean activity concentration (unit: $\mathrm{Bq} \mathrm{m}^{-3}$, equivalent to $\mathrm{m}^{-3} \mathrm{~s}^{-1}$ ) of species $i$ during the decay process (see Appendix A for detailed expression); $n_{\alpha}$ and $n_{\beta}$ denote the number of released particles; $E_{\alpha, i}$ and $E_{\beta, i}$ stand for the corresponding decay energy (unit: $\mathrm{eV}$ ); $E_{\alpha, p}$ and $E_{\beta, p}$ are the energy (unit: $\mathrm{eV}$ ) needed for producing one ion pair for $\alpha$ decay and $\beta$ decay, respectively.

The ionization rate induced by galactic cosmic rays is computed as in Kazil et al. (2010), which takes into account the 11-yr cycle of solar activity.

\subsection{Coupling of different processes}

In ECHAM5 there are four processes directly affecting the concentration of radon and its progeny. These are:

- $\mathcal{A}$ : large-scale advection;

- $\mathcal{T}$ : turbulent mixing (i.e., vertical diffusion) with radon emission as surface boundary condition;

- $\mathcal{D}$ : radioactive decay and ionization;

- $\mathcal{C}$ : cumulus convection.

The computation sequence can be summarized using the notation of Williamson (2002) as follows:

$$
\begin{array}{r}
c_{i}(t+\Delta t)=\mathcal{C}\left(\mathcal{D}\left\{\mathcal{T}\left[c_{i}(t-\Delta t)\right], \mathcal{A}\left[c_{i}(t-\Delta t)\right]\right\}\right) \\
(i=1,2,3) .
\end{array}
$$

Large-scale advection and turbulence are computed first, using process splitting in Williamson's terminology (or parallel splitting according to Dubal et al., 2004). Thereafter the radioactive decay and cumulus convection are computed using time splitting (sequential splitting). Note that the ECHAM5 model employs the leapfrog time stepping scheme, thus on the r.h.s. of Eq. (2) we start from time step $t-\Delta t$. This means the $c_{i}(t)$ and $\Delta t$ on the r.h.s. of Eqs. (A5)-(A13) are replaced by $c_{i}(t-\Delta t)$ and $2 \Delta t$, respectively.

\subsection{Simulations}

Numerical simulations are carried out for the period 1 October 1998-31 December 2003 forced by the AMIP II sea surface temperature and sea ice cover (Taylor et al., 2000). The model meteorology is constrained by the ERA40 reanalysis (Uppala et al., 2005) using the nudging technique (Jeuken et al., 1996). "Free" runs without nudging are also performed and briefly discussed in Sect. 3.3.

As already mentioned earlier, three simulations are performed with different radon emission maps: one with the WCRP1995 recommendation, one with the scaled Schery and Wasiolek (1998) map, and the third with the new map compiled in this study (Fig. 2). In the merged map, the global average radon emission flux over land between $60^{\circ} \mathrm{S}$ and $60^{\circ} \mathrm{N}$ is around 0.96 atom $\mathrm{cm}^{-2} \mathrm{~s}^{-1}$ (Table 1). In the scaled SW1998 map we have reset the flux over the oceans to zero, because a preliminary simulation revealed that the constant flux of 0.00417 atom $\mathrm{cm}^{-2} \mathrm{~s}^{-1}$ over the ocean caused unacceptably high radon concentration at many locations.

In our simulations, the initial concentrations of all radioactive species are set to zero. 3-hourly instantaneous tracer concentrations and ionization rate are archived as well as the monthly means. The first three months of the simulation period are discarded as spin-up. 


\section{Radon concentration in the lower troposphere}

In this section we present the simulated surface radon concentration, compare the results obtained using different emission maps, and evaluate the simulations against measurements. For clarity, we emphasize again that in this paper the amount of radon in the air is described by its activity concentration and we use the unit $\mathrm{mBq} \mathrm{m}^{-3}$ STP, i.e., millibecquerel per cubic meter at the standard atmospheric condition $(273.15 \mathrm{~K}, 1013.25 \mathrm{hPa})$ to compare different sets of data and model results. When discussing radon emission, we follow the convention and use the atom number flux (unit: atom $\mathrm{cm}^{-2} \mathrm{~s}^{-1}$ ).

\subsection{Measurements}

Zhang et al. (2008) used surface radon measurements at 28 sites to evaluate radon transport in a global model. In this study we have extended that data set by including recent measurements from observers and publications, as well as some earlier data of the period 1955-1987. One site used in Zhang et al. (2008), Puy de Dome, is excluded here because it is strongly affected by small-scale topography that can not be resolved in climate models at the resolution we have chosen. There are some studies in the literature which reported on annual mean radon concentrations but without seasonal variation (e.g., Lockhart et al., 1966; Nagaraja et al., 2003). These data are not included in our analysis. Detailed information about the measurements used in this study and their references are given in Table 2. The sites are shown in Fig. 3. As radon measurements at some locations were reported in other units, they are converted to $\mathrm{mBq} \mathrm{m}^{-3}$ STP. For quantitative comparison between observation and simulation, model output is linearly interpolated to the location of the observations.

It should be noted that the data listed in Table 2 were measured using different methods (e.g. one-filter method and two-filter method). The difference between measured radon concentrations by using different methods at the same location could be a few ten percents under certain conditions (Xia et al., 2010). The one-filter method, for example, needs an assumption about the disequilibrium factor between counted progeny and its precursor radon (Levin et al., 2002). The disequilibrium factor depends on local meteorological conditions and the height of the air inlet above ground and could vary with time. For some measurement methods, it could be possible, that the system can not separate thoron progenies from radon progenies and the whole detected activity is accounted to radon (C. Schlosser, personal communication, 2010). We should take these uncertainties into account when comparing the model with measurements collected by using different instruments.

\subsection{Overview of model results}

The scatter plots in Fig. 4 provide a compact overview of the model results in comparison with measurements. Each point in the figure represents one seasonal or monthly mean at one site. At the locations where measurements are available at frequencies higher than monthly, we compute the monthly mean before making the plot; at the places where only seasonal data are available, we simply take the seasonal mean, and average the model results accordingly.

On the whole, all three simulations agree reasonably well with the observations. Taking into account all seasons and sites, more than $70 \%$ samples are consistent with observation within a factor of 2 . The winter and summer results are of similar quality. The outliers in Fig. $4 \mathrm{a}$ and g indicate the underestimation of radon concentrations at Dumont d'Urville (especially in summer), which will be discussed in Sect. 3.4. Comparing the three columns in Fig. 4, one can see clearly that the merged emission map leads to better results than the other two simulations. The correlation between simulation and observation increases significantly. The overestimated concentrations in the WCRP1995 and scaled SW1998 simulations in the range between $4 \times 10^{2}-$ $6 \times 10^{3} \mathrm{mBq} \mathrm{m}^{-3}$ STP are improved considerably.

To identify the reasons for the improvement, results in different regions are shown separately in Fig. 5. In the European regions southward of $60^{\circ} \mathrm{N}$ (excluding the Iberian Peninsula), the WCRP1995 flux of 1 atom cm $\mathrm{c}^{-2} \mathrm{~s}^{-1}$ is considerably stronger than the other two emission setups (cf. Fig. 2), thus in Fig. 5a the green dots reveal clear overestimation compared to the other two panels in the same row. Over Scandinavia the WCRP1995 and SW1998 fluxes are about 0.5 atom $\mathrm{cm}^{-2} \mathrm{~s}^{-1}$ at most grid points, which seems still too high since almost all the pink markers in Fig. 5a and $\mathrm{b}$ lie outside the factor of 2 region. In contrast, the emissions derived by Szegvary et al. (2007) from the terrestrial gamma dose lead to much better results in this region (Fig. 5c).

India and China are characterized by high radon emission and strong spatial gradient, in the soil and other soil conditions such as soil wetness and temperature (Schery, 2004; Zhuo et al., 2008). The constant flux of WCRP1995 thus causes relatively low simulation-to-observation correlation and a clear underestimate in surface radon concentration (Fig. 4d). The scaled SW1998 map results in a better correlation, while the data from Zhuo et al. (2008) in China (used in our merged map) provide the most realistic results in the second row of Fig. 4. A similar situation can be seen for the United States, although biases associated with the scaled SW1998 are positive. In South America the three simulations are not very different. Our merged map uses the same emission as the scaled SW1998 map, thus gives almost identical results; the WCRP1995 emission leads to reasonable, although slightly overestimated surface concentration. 

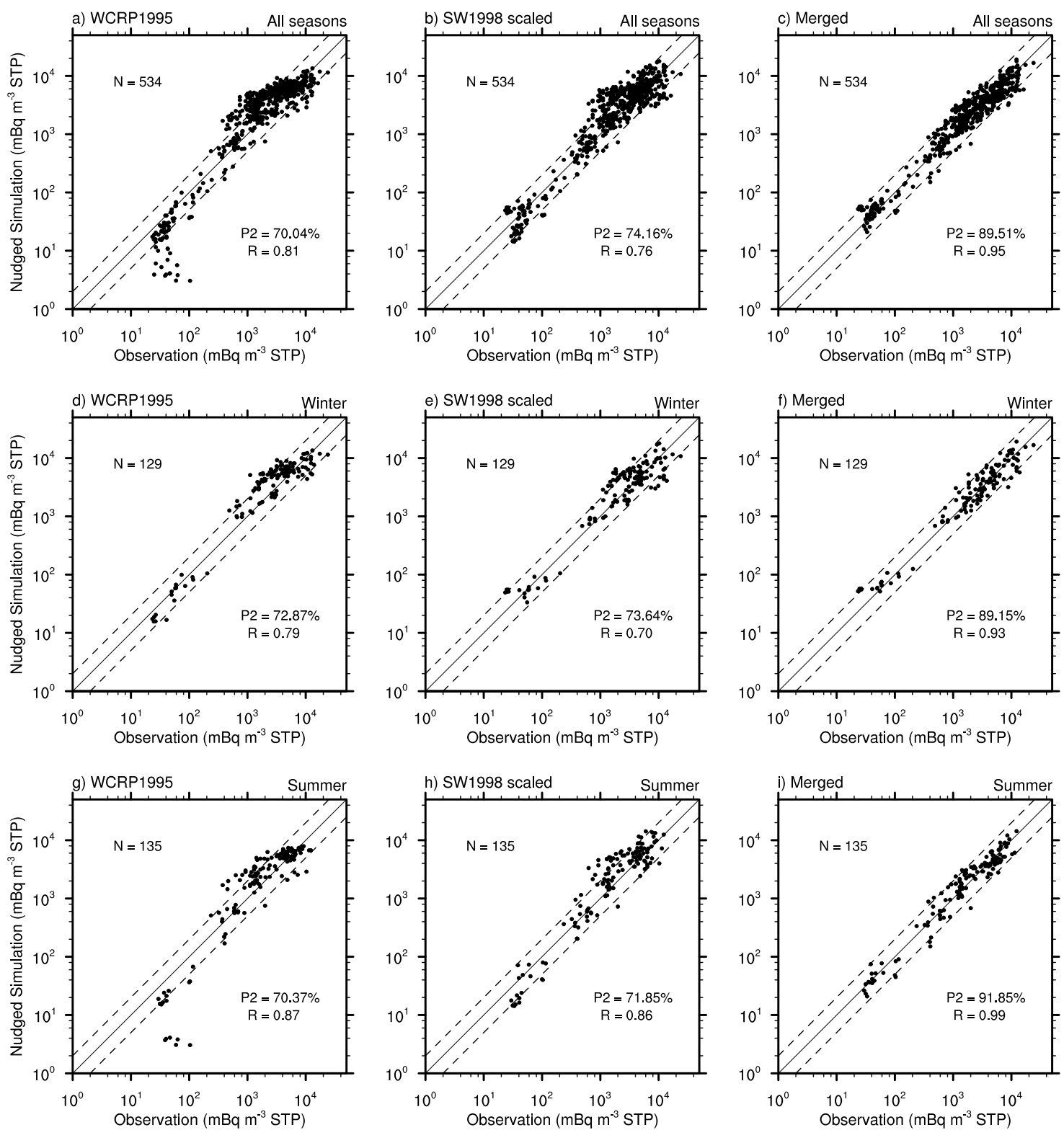

Fig. 4. Scatter plots of the simulated and measured monthly or seasonal mean surface radon concentration $\left(\mathrm{mBq} \mathrm{m}^{-3} \mathrm{STP}\right)$ at the 51 sites listed in Table 2 and shown in Fig. 3. The three columns correspond to simulations using the WCRP1995 recommended radon emission (left), the SW1998 emission maps scaled by a factor of 1/1.6 (middle), and the new emission maps prepared during this study. The first row contains results of all months/seasons (534 samples); The second row shows the 129 winter samples (DJF in the Northern Hemisphere, JJA in the Southern Hemisphere), and the third row shows only the 135 summer samples (JJA in the Northern Hemisphere, DJF in the Southern Hemisphere). The dashed lines indicate the range within a factor of 2 of the measurements. Also shown in each panel are the percentage of samples within this range (the P2 values) and the correlation coefficients between simulation and observation (the $R$ values).

\subsection{Nudged versus climatological simulations}

As mentioned in the previous section, we have also performed simulations without nudging the model meteorology toward reanalysis. The main purpose is to evaluate the ECHAM5 model's ability in tracer transport in a case of "free" simulation. It turns out that without nudging, the sim- ulated radon concentration still compares well with the measurements. To demonstrate this, we present in Fig. 6 the comparison between simulated and observed monthly mean concentrations for all the sites shown in Fig. 3. On the whole the results are very similar to the nudged simulations (Fig. 4). The correlation coefficients and factor of 2 percentages are slightly lower than in the nudged runs due to less accurate 

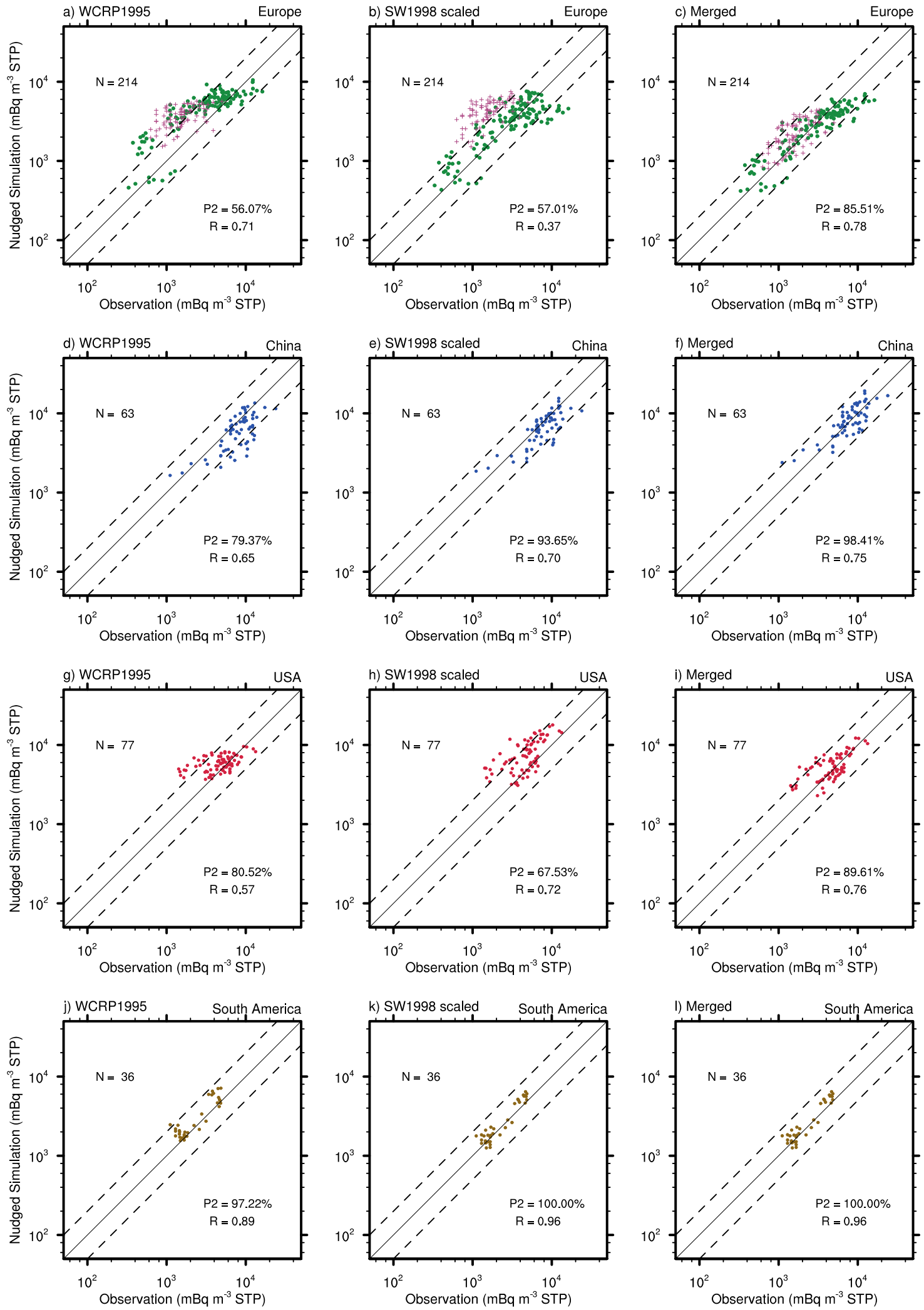

Fig. 5. Same as Fig. 4, but focusing on different regions. The four rows show results in (from top to bottom) Europe, China, the United States and South America. All seasons are included. The marker colors are consistent with Fig. 3. 

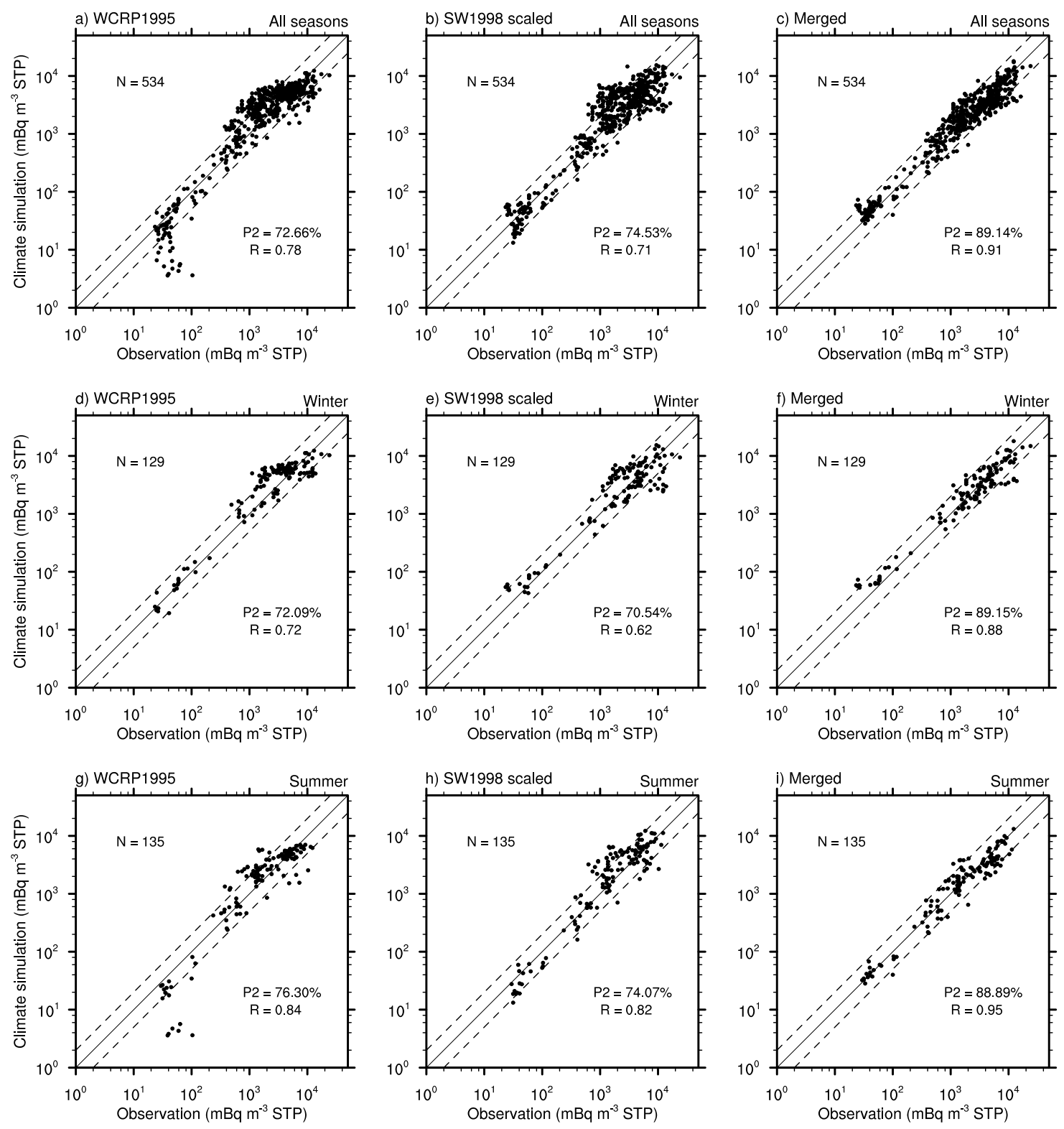

Fig. 6. Same as Fig. 4, but for the climatological simulations without nudging.

meteorological fields. However, there is no severe deterioration of the overall quality in any of the simulations.

\subsection{Radon concentration at individual sites}

The scatter plots discussed above are derived from seasonal or monthly mean surface radon concentrations. The correlation between simulation and observation is mainly determined by the model's ability to reproduce the spatial distribution of radon concentration at regional to global scales. In this subsection we zoom in to individual sites to evaluate the simulated temporal distribution and seasonal cycle by analyzing the box plots in Figs. 7-10.
A box plot provides detailed information on distribution statistics. The two whiskers attached to each box denote the 10th (lower) and 90th (upper) percentiles. The lower and upper hinges are the 25th and 75th percentiles, respectively, which bound the middle half of the population. The middle hinge and the dot are the population median and mean, respectively. In the figures, boxes are drawn for all samples at the site, and for each season separately. The observed distribution is shown in black; simulation with the WCRP1995 emission is shown in green, the scaled SW1998 map in blue, and the merged map in red. The simulated distributions are derived from 3-hourly model output. The observed distributions are derived from the original high frequency data if 

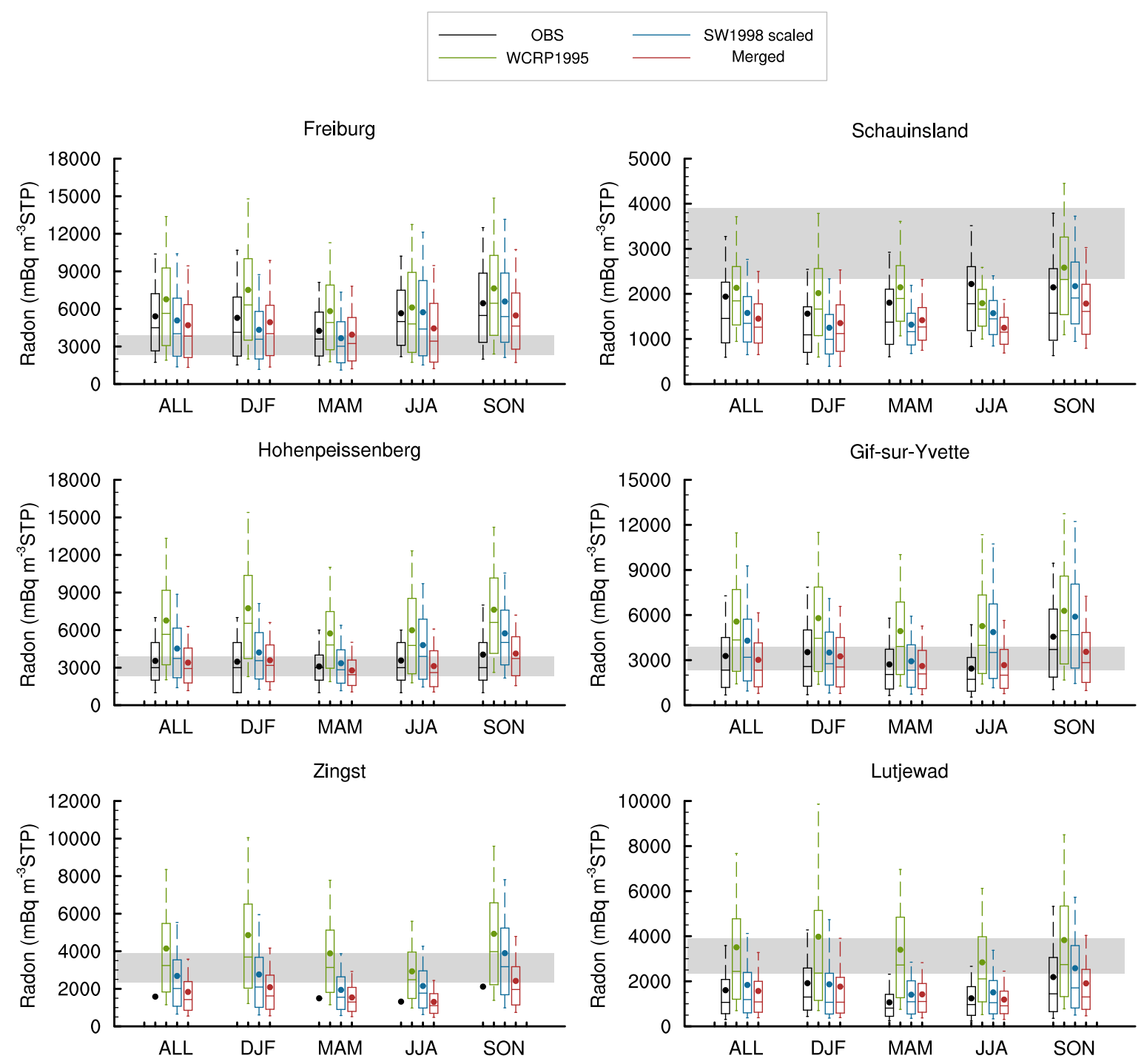

Fig. 7. Box plots showing the simulated and observed distribution of surface radon concentration at six sites in Europe. The two whiskers of each box denote the 10th (lower) and 90th (upper) percentiles. Hinges from bottom to top are the 25th, 50th, and 75th percentiles, respectively. Seasonal and annual means are indicated by dots. The gray areas indicate magnitude of the equivalent radon concentration that would lead to the same ionization rate as caused by galactic cosmic rays. The lower and upper boundaries of the gray areas correspond to the 10th and 90th percentiles, respectively. See paragraph 3 of Sect. 3.4 for further details.

available. At the sites where only monthly or seasonal mean can be obtained, the seasonal mean is plotted.

Following Kazil et al. (2010) we have diagnosed in our simulations the ion production caused by galactic cosmic rays (GCR). Assuming that in the near-surface layer radon and its progeny are in equilibrium, one can easily determine (see, e.g., Laakso et al., 2004) the radon activity concentration that would result in the same ionization rate (hereafter referred to as equivalent radon concentration). In Figs. 7-10, the lower and upper boundaries of the filled gray areas are the 10th and 90th percentiles of the equivalent radon concentrations. Note that these reference percentiles are not de- rived from data at each single site, but rather from the 3hourly model output at all surface grid points with altitude lower than $2000 \mathrm{~m}$. (Locations of surface elevation higher than $2000 \mathrm{~m}$ are excluded because they are exposed to much stronger GCR than lower altitudes, thus feature considerably higher ionization rate. In our study there are no measurements from such high elevations, except for those measured at Mauna Loa.) It should also be noted that in reality radon and its progeny are not always in equilibrium. The wide range of disequilibrium in individual measurements (see, e.g. Anspaugh et al., 2000) implies a degree of uncertainty in our estimate of the equivalent radon concentration described 

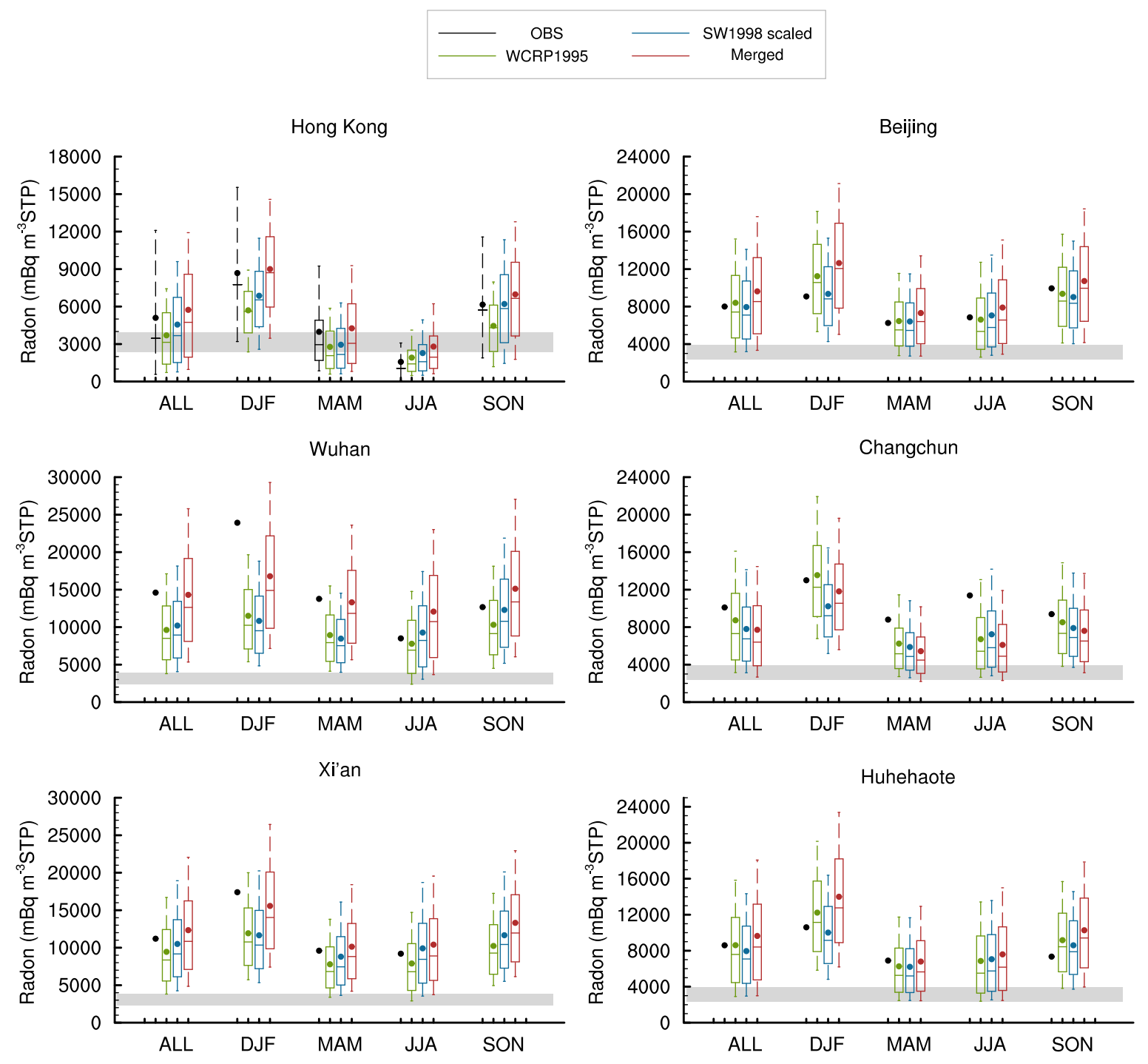

Fig. 8. Same as Fig. 7 but for six sites in China.

above. On the other hand, equilibrium factors between 0.5 and 0.7 are regarded as typical by Anspaugh et al. (2000) for outdoor environment, and the value 0.6 was recommended (see points 122 and 123 of Annex B therein). In other words, in a typical outdoor environment, the actual potential alpha energy concentration related to the short-lived progeny is about $50 \%-70 \%$ of the value that would prevail in the equilibrium case. Under such condition, the equivalent radon concentrations, corresponding to the cosmic ray ionisation rate, will be underestimated by (roughly) a factor of 2 . One should bear this uncertainty in mind when interpreting the box plots in Figs. 7-10.

The panels in Fig. 7 confirm our findings from the scatter plots that over Europe, the WCRP1995 emission is on the high side, while the merged map leads to most realistic results. At Freiburg, Schauinsland, Hohenpeissenberg, Gif-
sur-Yvette, and Lutjewad, where continuous and high frequency data (German Federal Office for Radiation Protection, Zellweger et al., 2006; Yver et al., 2009; van der Laan et al., 2009) allow for derivation of the concentration distribution, the simulated concentration populations agree quite well with measurements. One can also see in these panels that the seasonal variation of radon concentration is well simulated. It is worth noting that according to any of the emission maps in Fig. 2, Europe and Russia feature the lowest fluxes among all the continental areas (except for the icecovered Greenland and Antarctica). Even so, the observed and simulated radon concentration often exceeds the 90th percentile of the equivalent concentration derived from the GCR-induced ionization. 

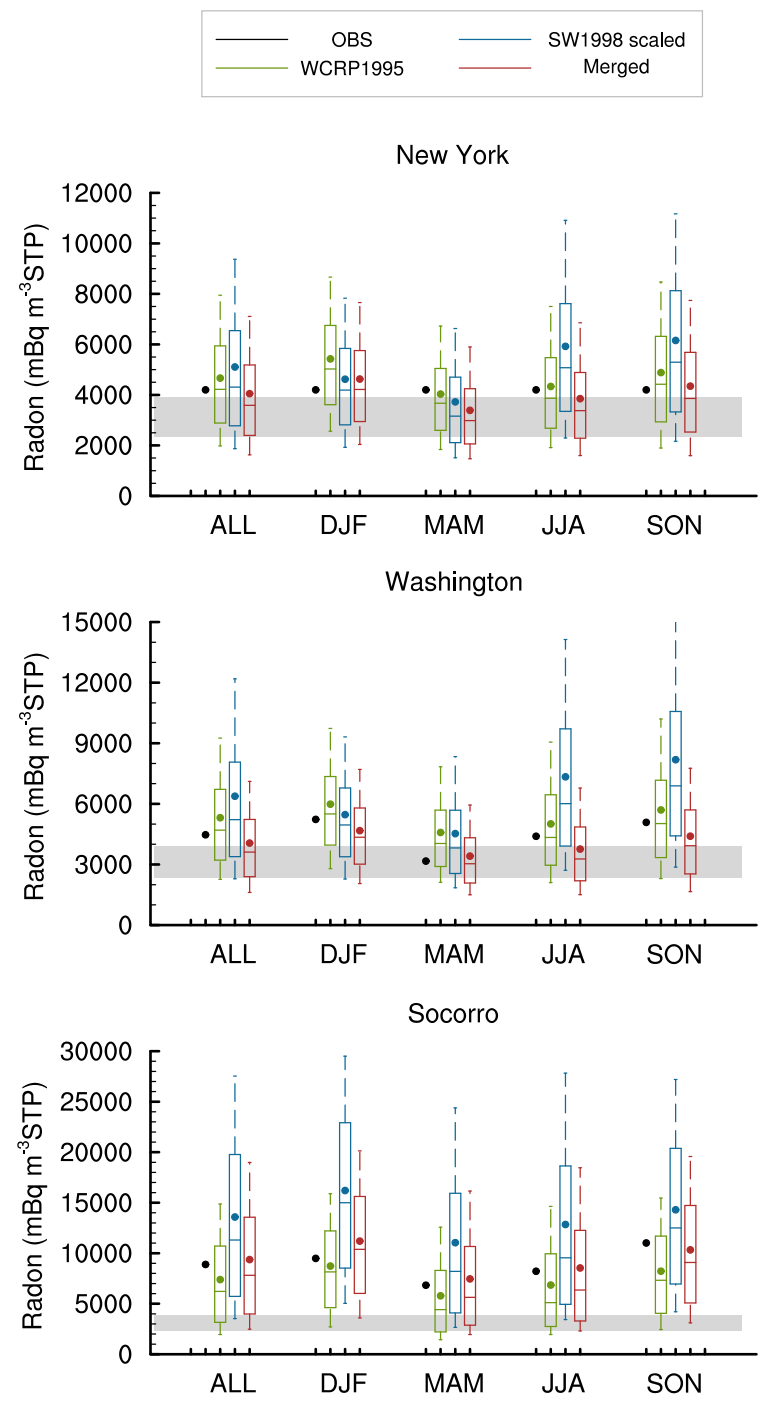

Fig. 9. Same as Fig. 7 but for three sites in the United States.

Figure 8 shows results at six Chinese sites. ${ }^{1}$ In the southern (e.g., Hongkong, Wuhan) and western (e.g., Xi' an) part of China, the simulated mean concentrations agree better with observations when the Zhuo et al. (2008) emissions are applied (see left column in Fig. 8). Note that the concentrations are typically at the order of $5000 \mathrm{mBq} \mathrm{m}^{-3}$ STP or higher, implying ionization rates of 3.2 pairs $\mathrm{cm}^{-3} \mathrm{~s}^{-1} \mathrm{STP}$ or stronger. Furthermore, it is worth noting that the selected

\footnotetext{
${ }^{1}$ The measurements from Hongkong (Zahorowski et al., 2005) were collected at Hok Tsui, an ACE-Asia (Aerosol Characterization Experiment in East Asia ) network site. Data of the five inland cities were taken from Jin et al. (1998), each sample of which was the average of measurements collected over bare soil at several outdoor locations in the same city. The individual locations were characterized by typical regional features in terms of soil type and meteorological conditions. These measurements thus represent typical radon concentrations in the corresponding regions.
}

cities are located in the East Asian monsoon region. The fact that the ECHAM5 model reasonably reproduces the seasonal cycle of surface radon concentration indicates that the East Asian monsoon circulation and its effect on large scale tracer transport is well represented by the model.

From Fig. 9 we see again that the SW1998 emission, even though scaled down by a factor of 1.6 , is too high in the USA. The inter-city differences suggest that taking into account the regional gradient in radon flux improves the results in general.

In Fig. 10, results are presented for eight coastal and remote ocean sites. Bermuda and Mauna Loa are typical examples of remote ocean sites, while Cape Grim and Cape Point are coastal sites, all strongly affected by horizontal transport. At these sites the model is able to reproduce not only the correct magnitude and seasonal cycle of the population mean, but also the characteristic shapes of the concentration distribution. The strongly asymmetric distributions at Cape Grim and Cape Point are well captured. This indicates that both the variations in large scale circulation and the radon emission in source regions are reasonably represented in the model.

Kerguelen and Crozet are also remote ocean sites, but feature extremely low radon concentration because of their location in the Southern Ocean. At these two sites we again see a strong sensitivity to emission. Over the ocean, both the WCRP1995 recommendation and the modified SW1998 map have zero radon flux, while the merged emission map utilizes the space- and time-dependent estimates of Schery and Huang (2004). In the storm track over the Southern Ocean, the surface radon flux are relatively large due to strong surface winds. In the region $40^{\circ} \mathrm{S}-60^{\circ} \mathrm{S}, 0^{\circ} \mathrm{E}-180^{\circ}$, the annual mean exceeds 0.005 atom $\mathrm{cm}^{-2} \mathrm{~s}^{-1}$ (cf. Fig. 1 in Schery and Huang, 2004). Although the flux is very weak compared to that over the continents, taking it into account does improve the results over the remote oceans significantly (Fig. 10, row 3).

Simulating radon concentration at Dumont d'Urville in Antarctica has always been a difficult task (see, e.g., Heimann et al., 1990; Taguchi et al., 2002; Josse et al., 2004). When assuming zero local emissions, radon concentration at this site is completely determined by longrange transport. This is what happens in the simulation using the WCRP1995 emission setup. Note that WCRP1995 specified zero emission also over the oceans, thus all the radon atoms over Antarctica originate from other continents. In this simulation we get not only unacceptably low concentrations at Dumont d'Urville and Mawson, but also wrong seasonal cycles that completely disagree with observations (see green boxes in the last row of Fig. 10). The scaled SW1998 map and the merged emission assume a constant flux of 0.00417 atom $\mathrm{cm}^{-2} \mathrm{~s}^{-1}$ over Antarctica all year round, which results in a much better seasonal cycle in the simulated radon concentration, although the values are now on the high side. We have performed an additional experiment using the merged emission map, but set the radon flux 

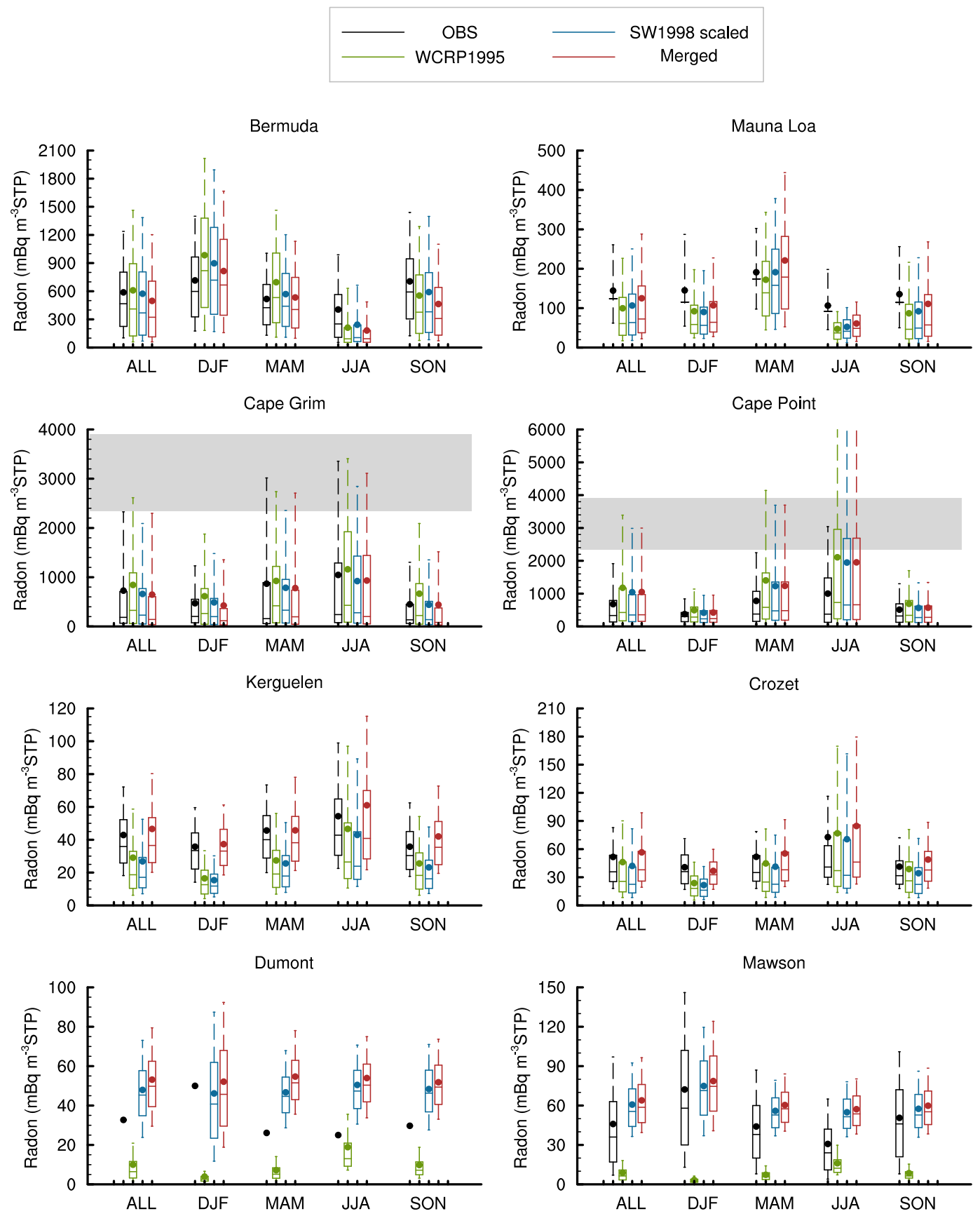

Fig. 10. Same as Fig. 7 but for coastal and oceanic sites. Most panels in this figure do not have a gray box in them because at these sites the radon family induces much less ionizing energy than the cosmic rays. The gray box is therefore literally off the chart.

over Antarctica to zero. Compared to WCRP1995, this simulation has non-zero fluxes over the Southern Oceans (Schery and Huang, 2004), which, through transport, can affect Antarctica. It turns out that the concentrations at Dumont d'Urville and Mawson become slightly higher than in the WCRP1995 simulation (not shown), but there is no essential improvement either in the magnitude of the concentration or in its seasonal cycle. This indicates that (at least in the ECHAM5 model) transport from the ocean and remote continents alone can not explain the observed radon concentration over Antarctica. Local emissions need to be included. Ideally one should replace the constant radon flux of 0.00417 atom $\mathrm{cm}^{-2} \mathrm{~s}^{-1}$ by some detailed map with horizontal and seasonal variation. This can not be achieved now due to severe lack of measurements in this region. 

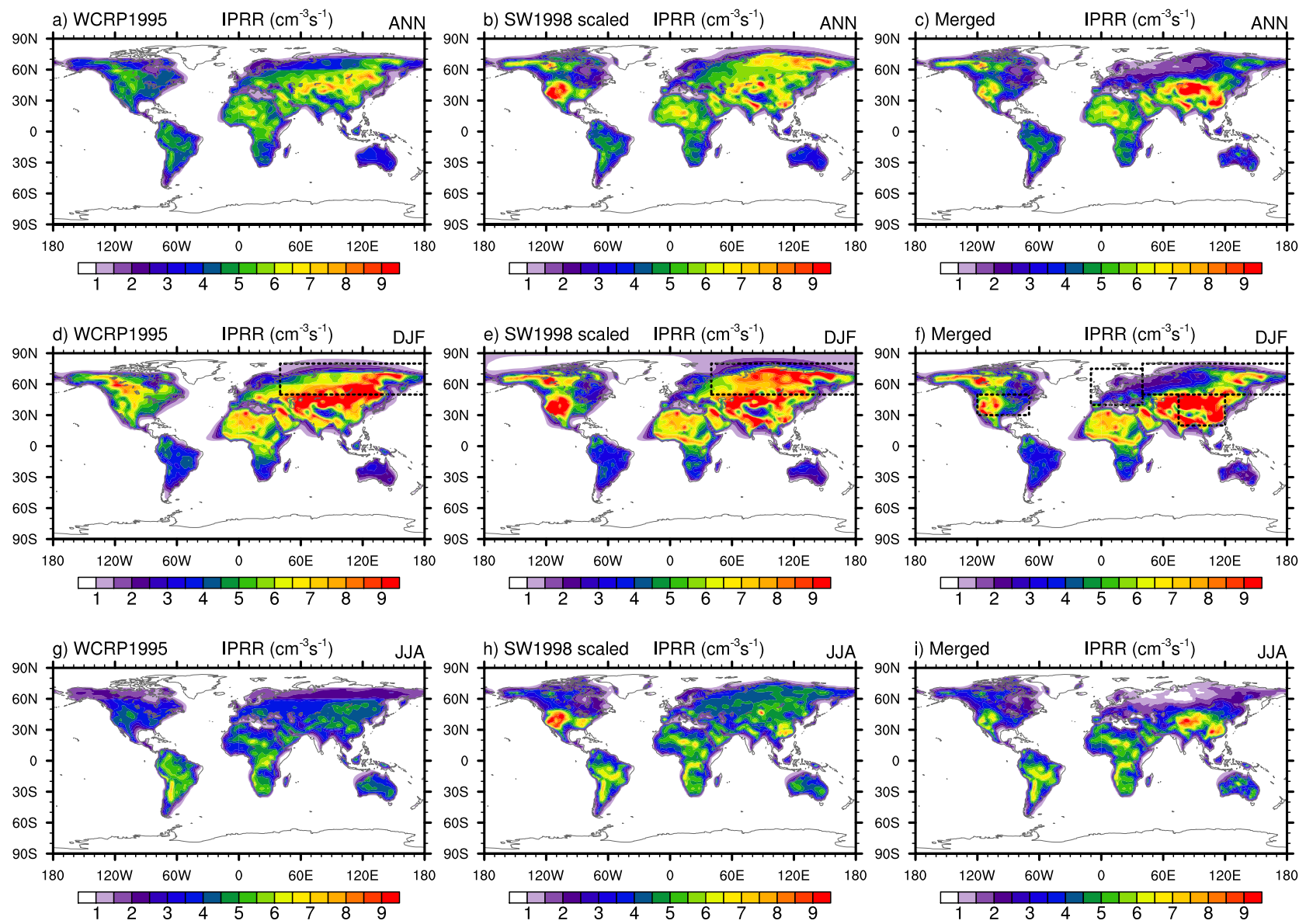

Fig. 11. Simulated annual and seasonal mean near-surface ionization rate induced by radon decay series (IPRR, unit: $\mathrm{cm}^{-3} \mathrm{~s}^{-1}$ ).

\subsection{A brief summary on model evaluation}

From the analysis presented in this section, we see that the ECHAM5 model performs reasonably well in simulating the lifecycle and global distribution of radon. Using the most up-to-date emission estimates, we are able to reproduce the main features of the temporal and spatial distribution of the surface radon concentration. At most of the sites shown in Fig. 3, model results agree not only qualitatively but also quantitatively well with measurements. On the one hand, there is still quite some room for improvement, for example, by compiling even more detailed and accurate emission maps, and by enhancing the model resolution so as to better resolve the atmospheric circulation and surface properties at scales smaller than $200 \mathrm{~km}$; On the other hand, the simulations shown here are reasonable, and compare well with other models (see, e.g., Dentener et al., 1999; Taguchi et al., 2002; Hauglustaine et al., 2004; Koch et al., 2006, among others). This provides a solid base for estimating the radonrelated ionization rate.

\section{Radon-related ionization}

In this section we present the simulated ionization rate caused by radon and its progeny. In the simplified decay chain (Fig. 1b) there are three sources of ionizing radiation: the decay of ${ }^{222} \mathrm{Rn},{ }^{214} \mathrm{~Pb}$ and ${ }^{214} \mathrm{Bi}$. Since the lifetimes of the two daughters are relatively short compared to the model time step $(12 \mathrm{~min})$, their concentrations are not strongly affected by transport, but rather determined by how much radon is locally availably for radioactive decay. Thus the global distribution of the resulting ionization closely resembles that of radon concentration (not shown). For brevity, in the following we will refer to the radon-related ionization rate (i.e., variable $\psi$ in Eqn. 1) as IPRR.

\subsection{Global distribution}

Figure 11 displays the annual and seasonal mean IPRR in the surface layer simulated with different radon emission data. The highest ionization rates appear where there is strong emission and stable boundary layer. In boreal winter, the suppressed vertical transport due to increased atmospheric 

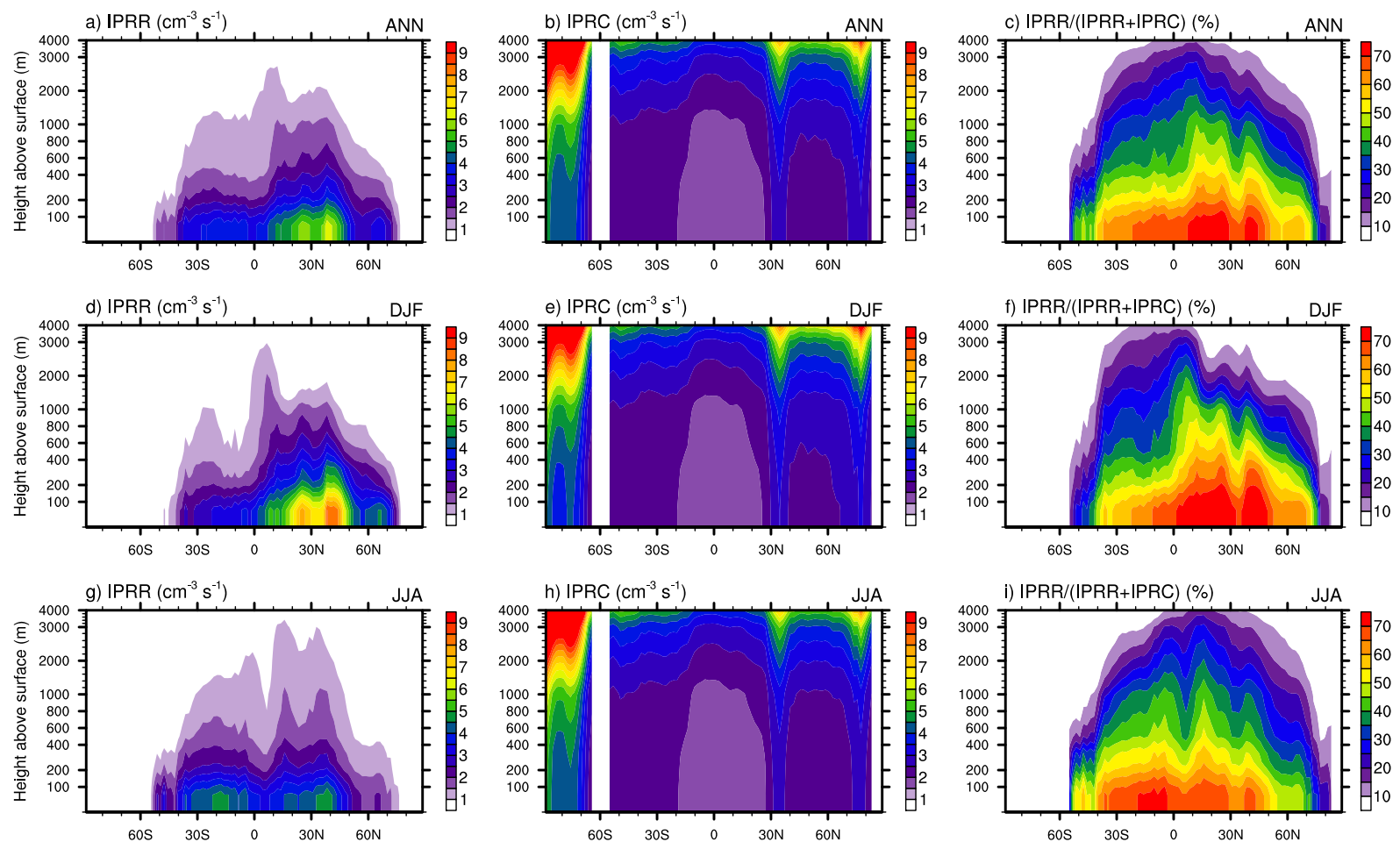

Fig. 12. Left column: simulated zonal mean ionization rate over the continents caused by the radioactive decay of radon and its progeny (IPRR, unit: $\mathrm{cm}^{-3} \mathrm{~s}^{-1}$ ); Middle column: as in the left column but caused by galactic cosmic rays (IPRC, unit: $\mathrm{cm}^{-3} \mathrm{~s}^{-1}$ ); Right column: the contribution of radon and its progeny to the total (IPRR + IPRC) ionization rate. All panels correspond to the simulation performed with the merged emission map.

stability leads to high IPRR over $9 \mathrm{~cm}^{-3} \mathrm{~s}^{-1}$ (Fig. 11d-f). The summer ionization rates are considerably lower due to the ventilation effect of convective transport (Fig. 11g-i).

Discrepancies among the three columns in Fig. 11 indicate the impact of radon emission. The scaled SW1998 map leads to stronger ionization over West US and Europe than in the other two simulations, while in China the IPRR is highest when the Zhuo et al. (2008) emission is applied (Fig. 11c, f, i). These are all consistent with what we have seen in Fig. 2. Considering the model evaluation results in Sect. 3, the IPRR given by the merged emission map is probably the most accurate in the above-mentioned regions. It is worth noting that panels d-f of Fig. 11 reveal large discrepancies over Russia as well. There the SW1998 emission map gives the highest IPRR among the three simulations (Fig. 11e), while the Szegvary et al. (2007) emission corresponds to the lowest values (Fig. 11f). Due to lack of long-term observation, we are not yet able to judge the quality of the simulations in this area. Nevertheless differences between the two panels are still informative because they provide an (although far from conclusive) estimate about the uncertainty of the IPRR in this area.

It would be useful if we could compare the simulated radon-induced ionization rate with some direct ionization rate measurements (e.g, Gagné et al., 2010). However, un- like the radon concentration, the ionization rate induced by the radon family can not be directly measured but has to be derived. One way is to subtract the external ionization from the observed total amount and attribute the residual to the radon family, assuming that there is no other radionuclide in the air. The second and often used method is to compute the radon-induced ionization rate from the activity concentrations of radon and its progeny. The problem here is that not all the daughters can be directly measured. Before computing the ionization rate, one has to first derive the activity concentration of these unmeasurable daughters by assuming a certain equilibrium factor (Anspaugh et al., 2000) for the decay chain. Both of the two methods need additional information of other ionization agents and assumptions made would bring additional uncertainty. Therefore, we are not able to get accurate measurements of radon-induced ionization rate and use them to evaluate the model directly.

Figure 12 presents the annual and seasonal mean IPRR in the lower troposphere in terms of zonal mean over land area, and compares them with the GCR-induced ionization. The radon-related ionization, primarily determined by radon emission and transport, shows a completely different pattern compared to the GCR-induced counterpart. The radon-related ionization is more concentrated in the lower troposphere and in middle- and low-latitude areas, where 

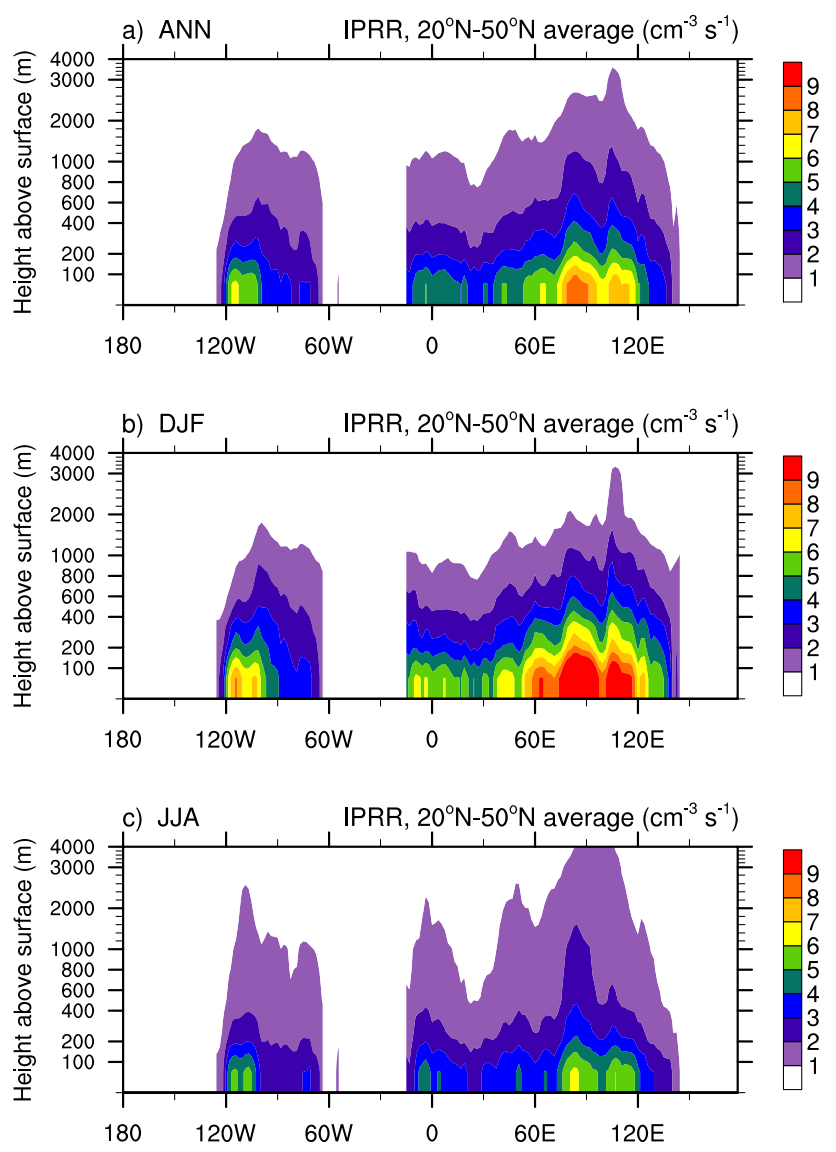

Fig. 13. Height-longitude cross section of the $20^{\circ} \mathrm{N}-50^{\circ} \mathrm{N}$ mean ionization rate over land caused by radon and its progeny. The results are obtained using the newly merged radon emission map.

its magnitude clearly exceeds the GCR-induced ionization (Fig. 12, right most column). It should be noted that in boreal winter, very high ionization rates appear between $20^{\circ} \mathrm{N}$ and $50^{\circ} \mathrm{N}$ (Fig. 12d). The major contributor to these maxima in the zonal mean is the high IPRR in Asia (China, Myanmar, and north of India) and the US, as can be seen from the eastwest cross section in Fig. 13. These regions are known to be associated with relative high near-surface $\mathrm{SO}_{2}$ and $\mathrm{H}_{2} \mathrm{SO}_{4}$ concentrations as well as nucleation rates (see, e.g., Figs. 12 in $\mathrm{Yu}$ et al. (2008)), especially in cold seasons when $\mathrm{SO}_{2}$ emissions are strong and the stable atmospheric boundary layer traps the species in the surface layer. Under such conditions, the coexistence of high ionization rate may help further enhance the particle formation prcesses.

\subsection{Ionization rate and ambient temperature}

Temperature and $\mathrm{H}_{2} \mathrm{SO}_{4}$ concentration are generally believed as the two most important factors controlling the start and end of nucleation events (see, e.g, Yu, 2010). In this subsection we intend to look into the coexistence of ionization with these parameters. Due to the fact that we did not switch on aerosol and chemistry processes in the simulations, concentrations of $\mathrm{H}_{2} \mathrm{SO}_{4}$ are not available. Thus only the ambient temperature is analyzed here.

Figure 14 shows the joint probability density distribution (PDF) of air temperature and radon-related ionization rate in different regions (China, Europe, North America, and Russia, as indicated in Fig. 11e-f by dashed black lines). The PDFs are computed for the lowest model level using the 3hourly data in winter (DJF). According to the evaluations in the previous section, the simulation using the merged radon emission is the most accurate in China, Europe, and North America. Therefore only this simulation is shown for these regions (Fig. 14a-c).

The most prominent feature in the first row of Fig. 14 is that ionization is much stronger over China and associated with lower temperature. The PDF of temperature peaks around $260 \mathrm{~K}$. At this temperature, ionization rate of $15 \mathrm{~cm}^{-3} \mathrm{~s}^{-1}$ is not at all uncommon (Fig. 14a). In extreme cases, the ionization rate can even reach $50 \mathrm{~cm}^{-3} \mathrm{~s}^{-1}$ at temperatures as low as $250 \mathrm{~K}$ (not shown). If there is abundant sulfuric acid gas, charged $\mathrm{H}_{2} \mathrm{SO}_{4} / \mathrm{H}_{2} \mathrm{O}$ nucleation may be strong and significantly influence the aerosol size distribution. In the US, ionization is also strong, and peaks around $0{ }^{\circ} \mathrm{C}$ (Fig. 14b). Europe, on the other hand, features very low ionization rate which probably has very limited influence on nucleation. The second row of Fig. 14 shows the joint PDF in Russia for all three simulations since it is not clear which one is more accurate. Although the simulated ionization rates are lower than in China and the US, the effect of low temperature may play a role and still leads to significant particle formation if other conditions of nucleation are fulfilled.

It should be pointed out that with Fig. 14 we only presented a very preliminary analysis showing that radon-related ionization may play a significant role in new particle formation at particular locations. In order to obtain more concrete results on the actual impact of such ionization, one should actually include the radon-related ionization in an aerosolclimate model and carry out sensitivity studies, because in reality the nucleation processes are highly complex and nonlinear, and not yet well understood. For example, in this section we analyzed only boreal winter although nucleation events are often observed to peak in spring and fall (e.g., Laaksonen et al., 2008). It would be interesting to carry out simulations with the ECHAM5-HAM model (Stier et al., 2005) to find out whether the radon-family plays a role (at least in this particular model) in the phenomena.

\section{Conclusions}

In this study global simulations are performed with the ECHAM5 model to simulate radon activity in the lower troposphere and its effect on ion production. The decay chain of radon in the model is simplified by removing short-lived radon daughters. The solution of the decay equation is 

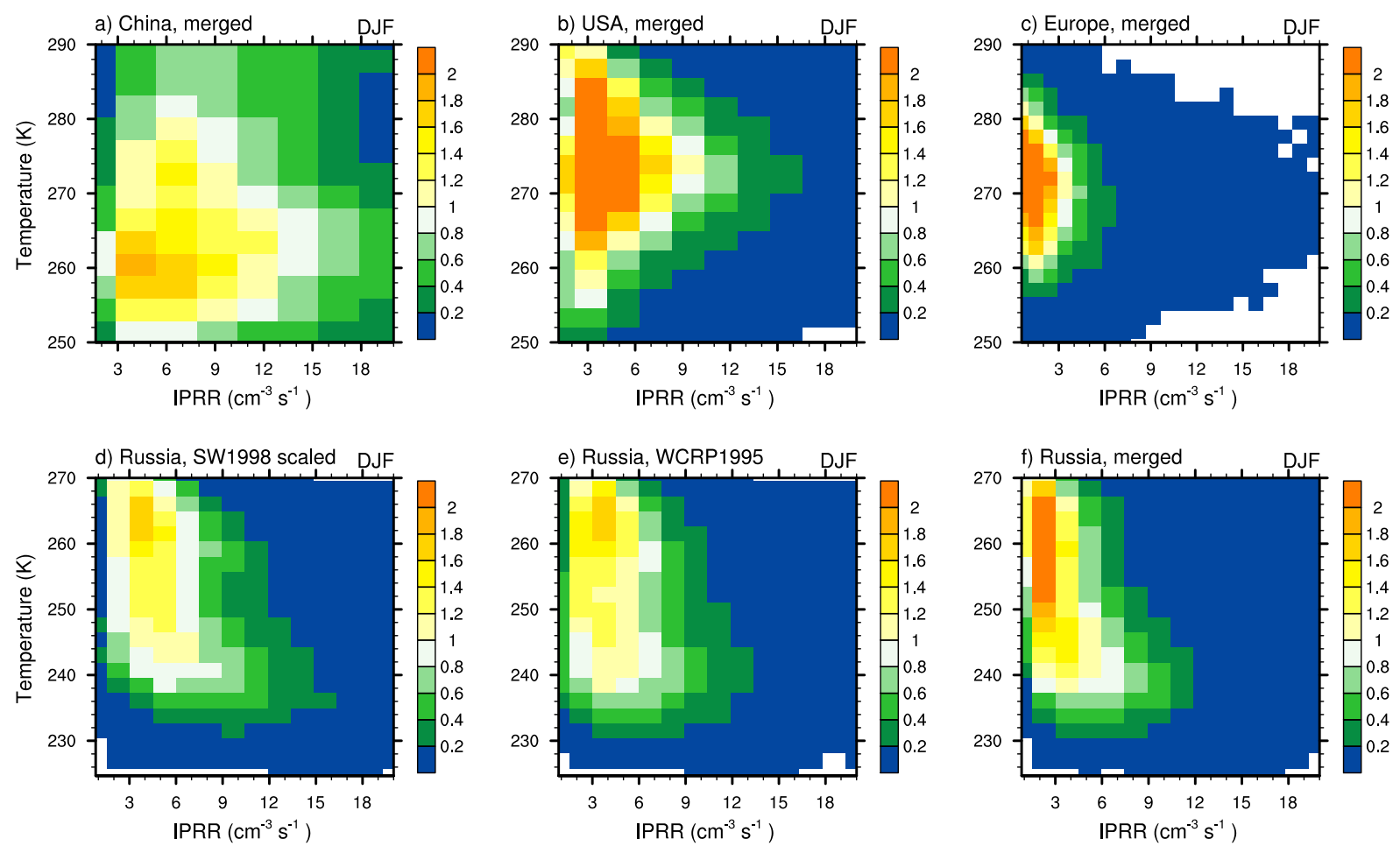

Fig. 14. Joint (bivariate) probability density distribution (PDF) of air temperature and radon-related ionization rate (IPRR) in different regions: (a) China $\left(20^{\circ} \mathrm{N}-50^{\circ} \mathrm{N}, 75^{\circ} \mathrm{E}-120^{\circ} \mathrm{E}\right)$; (b) Europe $\left(40^{\circ} \mathrm{N}-75^{\circ} \mathrm{N}, 10^{\circ} \mathrm{W}-40^{\circ} \mathrm{E}\right)$; (c) USA $\left(30^{\circ} \mathrm{N}-50^{\circ} \mathrm{N}, 120^{\circ} \mathrm{W}-70^{\circ} \mathrm{W}\right)$; (df) Russia $\left(50^{\circ} \mathrm{N}-80^{\circ} \mathrm{N}, 40^{\circ} \mathrm{E}-180^{\circ} \mathrm{E}\right)$. These regions are indicated by dashed black frames in Fig. 11 . Labels next to the color bar are intensities of the PDF (unit:\%). The PDFs are computed for the near-surface from the 3-hourly model output in winter months (DJF). Marginal area with white color indicate missing values. Note that scales of the temperature coordinate in (a-c) are not the same as those in (d-f).

computed analytically within each model time step, and coupled with tracer transport caused by advection, cumulus convection and turbulent mixing. The radon-related ionization rate is estimated based on the activity concentration of radon and its daughter species, and well-accepted values of the decay/ionization energy.

Based on recent reports in the literature on radon emission, an up-to-date global radon emission map is compiled with regional details and seasonal variation. The simulated radon activity concentration is evaluated against surface radon measurements at 51 locations. Results show that the global model ECHAM5 can reasonably reproduce the variations of surface radon concentrations observed at various locations. On the whole, the newly compiled emission map leads to better results compared to the WCRP1995 protocol and the widely used SW1998 map. The merged map is not only helpful for this study, but probably also useful for other researchers working on numerical modelling of radon transport and the transport and deposition processes of ${ }^{210} \mathrm{~Pb}$ (e.g., Balkanski et al., 1993).

The radon-related ionization rate is computed and compared with the GCR-ionization rate. It is found that in boreal winter, the suppressed vertical transport due to increased atmospheric stability leads to seasonal mean IPRR as high as $9 \mathrm{~cm}^{-3} \mathrm{~s}^{-1}$. In middle- and low-latitude continental areas, the zonal mean radon-induced ionization rate clearly exceeds the GCR-induced counterpart in the near-surface levels up to $800 \mathrm{~m}$ elevation. At many continental sites, the observed and simulated surface radon activity concentration often occurs well above the 90th percentile of the equivalent concentration derived from the GCR-induced ionization. Further analysis on the joint PDF of ionization rate and temperature show that in China and USA, strong radon-related ionization often occur in winter at low ambient temperature, which may help enhance the $\mathrm{H}_{2} \mathrm{SO}_{4} / \mathrm{H}_{2} \mathrm{O}$ nucleation when other factors such as $\mathrm{H}_{2} \mathrm{SO}_{4}$ concentration and relative humidity are in favorable conditions. Based on results from this study we conclude that it will be useful to extend the work of Kazil et al. (2010) and carry out a follow-up study with the aerosolclimate model ECHAM5-HAM to investigate the effect of radon-related ionization on nucleation, as well as the consequences in aerosol size distribution, cloud properties, and climate effect.

One of the products of this study, the monthly mean radoninduced ionization rates simulated by our model, are provided as a supplement of this paper which is freely available 
from the journal website. Ionization rates at higher temporal resolution, as well as the merged radon emission maps, can be provided to interested researchers upon request.

\section{Appendix A}

\section{Analytical solution of the decay chain}

The simplified decay chain system (Fig. 1b) can be described by an ordinary differential equation system with four unknowns (in activity concentration form):

$$
\begin{aligned}
\frac{d c_{1}}{d t} & =-\lambda_{1} c_{1}, \\
\frac{d c_{2}}{d t} & =\frac{\lambda_{1}}{\lambda_{2}} c_{1}-\lambda_{2} c_{2}, \\
\frac{d c_{3}}{d t} & =\frac{\lambda_{2}}{\lambda_{3}} c_{2}-\lambda_{3} c_{3}, \\
\frac{d c_{4}}{d t} & =\frac{\lambda_{3}}{\lambda_{4}} c_{3},
\end{aligned}
$$

where $c_{1}, c_{2}, c_{3}$, and $c_{4}$ are the activity concentration of ${ }^{222} \mathrm{Rn},{ }^{214} \mathrm{~Pb},{ }^{214} \mathrm{Bi}$, and ${ }^{210} \mathrm{~Pb}$, respectively, and $\lambda_{1}, \lambda_{2}$, $\lambda_{3}$, and $\lambda_{4}$ are the corresponding decay constants. For each model time step ( $\Delta t=12 \mathrm{~min}$ ), the analytical solution of the decay chain at $t+\Delta t$ reads

$$
\begin{aligned}
c_{1}(t+\Delta t) & =c_{1}(t) e^{-\lambda_{1} \Delta t} \\
c_{2}(t+\Delta t) & =c_{2}(t) e^{-\lambda_{2} \Delta t}+\chi_{21} \eta_{12} c_{1}(t), \\
c_{3}(t+\Delta t) & =c_{3}(t) e^{-\lambda_{3} \Delta t}+\chi_{21} \chi_{31} \eta_{13} c_{1}(t) \\
& +\chi_{32} \eta_{23}\left(c_{2}(t)-\chi_{21} c_{1}(t)\right)
\end{aligned}
$$

where

$$
\begin{aligned}
\chi_{i j} & =\frac{\lambda_{i}}{\lambda_{i}-\lambda_{j}}, \\
\eta_{i j} & =e^{-\lambda_{i} \Delta t}-e^{-\lambda_{j} \Delta t} .
\end{aligned}
$$

By integrating Eqs. (A5)-(A7) from $t$ to $t+\Delta t$, the time-step average concentration can be obtained:

$$
\begin{aligned}
\bar{c}_{1} & =\theta_{1} c_{1}(t) \\
\bar{c}_{2} & =\theta_{2} c_{2}(t)+\chi_{21}\left(\theta_{1}-\theta_{2}\right) c_{1}(t), \\
\bar{c}_{3} & =\theta_{3} c_{3}(t)+\chi_{21} \chi_{31}\left(\theta_{1}-\theta_{3}\right) c_{1}(t) \\
& \quad+\chi_{32}\left(\theta_{2}-\theta_{3}\right)\left(c_{2}(t)-\chi_{21} c_{1}(t)\right) .
\end{aligned}
$$

where

$$
\theta_{i}=\frac{\lambda_{i}-e^{-\lambda_{i} \Delta t}}{\lambda_{i} \Delta t} .
$$

Since the decay of ${ }^{210} \mathrm{~Pb}$ is ignored, its concentration is not computed in the model.

\section{Supplement related to this article is available online at: http://www.atmos-chem-phys.net/11/7817/2011/ acp-11-7817-2011-supplement.pdf.}

Acknowledgements. The authors thank F. Conen and T. Szegvary for providing their radon flux maps, and S. Rast for preparing the nudging data and making the internal review. We are also grateful to S. Schery, S. Whittlestone, C. Schlosser, J.-F. Vinuesa, and the two anonymous reviewers for their very helpful comments. The German BfS, French RAMCES, and Australian ANSTO monitoring networks are acknowledged for providing the new radon measurements used in this study. This work was jointly supported by the Max Planck Society and the EUCAARI project. All simulations were performed at the German Climate Computing Center (Deutsches Klimarechenzentrum GmbH, DKRZ).

The service charges for this open access publication have been covered by the Max Planck Society.

Edited by: M. Schulz

\section{References}

Anspaugh, L., Bennett, B., Bouville, A., Burkart, W., Cox, R., Croft, J., Hall, P., Leenhouts, H., Muirhead, C., Ron, E., Savkin, M., Shrimpton, P., Stather, J., Thacker, J., and Wrixon, A.: Exposures from natural radiation sources, ANNEX $B$ of Sources and effects of ionizing radiation, UNSCEAR 2000 Report to the General Assembly, Tech. Rep. E.00.IX.3, United Nations Scientific Committee on the Effects of Atomic Radiation, New York, USA, 2000.

Bakwin, P. S., Zhao, C., Ussler, W., Tans, P. P., and Quesnell, E.: Measurements of carbon dioxide on a very tall tower, Tellus B, 47, 535-549, 1995.

Balkanski, Y. J., Jacob, D. J., Gardner, G. M., Graustein, W. C., and Turekian, K. K.: Transport and residence times of tropospheric aerosols inferred from a global three-dimensional simulation of Pb., J. Geophys. Res., 98, 20573-20586, 1993.

Brinkop, S. and Roeckner, E.: Sensitivity of a general circulationmodel to parameterizations of cloud-turbulence interactions inthe atmospheric boundary layer, Tellus A, 47, 197-220, 1995.

Brunke, E. G., Labuschagne, C., Parker, B., Scheel, H. E., and Whittlestone, S.: Baseline air mass selection at Cape Point, South Africa: application of ${ }^{222} \mathrm{Rn}$ and other filter criteria to $\mathrm{CO}_{2}$, Atmos. Environ., 38, 5693-5702, 2004.

Chevillard, A., Ciais, P., Karstens, U., Heimann, M., and Schmidt, M.: Transport of ${ }^{22} \mathrm{Rn}$ using the regional model REMO: a detailed comparison with measurements over Europe, Tellus B, 54, 850-871, 2002.

Clement, C. F. and Harrison, R. G.: The charging of radioactive aerosols, J. Aerosol Sci., 23, 481-504, 1992.

Conen, F. and Robertson, L. B.: Latitudinal distribution of radon222 flux from continents, Tellus B, 54, 127-133, 2002.

Dentener, F., Feichter, J., and Jeuken, A.: Simulation of ${ }^{222}$ Radon using on-line and off-line global models, Tellus B, 51, 573-602, 1999.

Downey, A., Jasper, J. D., Gras, J. J., and Whittlestone, S.: Lower tropospheric transport over the Southern Ocean, J. Atmos. Chem., 11, 43-68, 1990.

Dubal, M., Wood, N., and Staniforth, A.: Analysis of parallel versus sequential splittings for time-stepping physical parameterizations, Mon. Weather Rev., 132, 121-132, 2004. 
Emsley, J.: Nature's building blocks: an A-Z guide to the elements, Oxford University Press Inc., New York, USA, 354-355, 2001.

Gagné, S., Nieminen, T., Kurtén, T., Manninen, H. E., Petäjä, T., Laakso, L., Kerminen, V.-M., Boy, M., Kulmala, M.: Factors influencing the contribution of ion-induced nucleation in a boreal forest, Finland, Atmos. Chem. Phys., 10, 3743-3757, doi:10.5194/acp-10-3743-2010, 2010.

Gold, S., Barkhau, H. W., Shleien, B., and Kahn, B.: Measurement of naturally occurring radionuclides in air, University of Chicago Press, Chicago, United States, 1964.

Goto, M., Moriizumi, J., Yamazawa, H., Iida, T., and Zhuo, W.: Estimation of global radon exhalation rate distribution, AIP Conf. Proc., 1034, 169-172, 2008.

Griffiths, A. D., Zahorowski, W., Element, A., and Werczynski, S.: A map of radon flux at the Australian land surface, Atmos. Chem. Phys., 10, 8969-8982, doi:10.5194/acp-10-8969-2010, 2010.

Guelle, W., Balkanski, Y. J., Schulz, M., Dulac, F., and Monfray, P.: Wet deposition in a global size-dependent aerosol transport model 1. Comparison of a 1 year ${ }^{210} \mathrm{~Pb}$ simulation with ground measurements, J. Geophys. Res., 103(D10), 11429-11445, 1998.

Harrison, R. G. and Carslaw, K. S.: Ion-aerosol-cloud processes in the lower atmosphere, Rev. Geophys., 41, 1012, doi:10.1029/2002RG000114, 2003.

Hatakka, J., Aalto, T., Aaltonen, V., and Aurela, M.: Overview of the atmospheric research activities and results at Pallas GAW station, Boreal Environ. Res., 8, 365-383, 2003.

Hauglustaine, D. A., Hourdin, F., Jourdain, L., Filiberti, M. A., Walters, S., Lamarque, J. F., and Holland, E. A.: Interactive chemistry in the laboratoire de meteorologie dynamique general circulation model, J. Geophys. Res., 109, D04314, doi:10.1029/2003JD003957, 2004.

Heimann, M., Monfray, P., and Polian, G.: Modeling the long-range transport of ${ }^{222} \mathrm{Rn}$ to subantarctic and arctic areas, Tellus B, 42, 83-99, 1990.

Hirao, S., Nono, Y., Yamazawa, H., Moriizumi, J., Iida, T., and Yoshioka, K.: Development and verification of long-range atmospheric transport model of radon-222 and lead-210 including scavenging process, in: The Natural Radiation Environment, edited by: Paschoa, A. S. and Steinhäusler, F., vol. 1034, American Institute of Physics, Buzios, Brazil, 407-410, 2008.

Hosler, C. R.: Urban-rural climatology of atmospheric radon concentration, J. Geophys. Res., 73, 1155-1166, 1968.

Hutter, A. R., Larsen, R. J., Maring, H., and Merrill, J. T.: ${ }^{222} \mathrm{Rn}$ at Bermuda and Mauna Loa: local and distant sources, J. Radioanal. Nucl. Ch., 193, 309-318, 1995.

Jacob, D. J. and Prather, M. J.: Radon-222 as a test of convective transport in a general circulation model, Tellus B, 42, 118-134, 1990.

Jacob, D. J., Prather, M. J., Rasch, P. J., Shia, R.-L., Balkanski, Y. J., Beagley, S. R., Bergmann, D. J., Blackshear, W. T., Brown, M., Chiba, M., Chipperfield, M. P., Grandpré, J., Dignon, J. E., Feichter, J., Genthon, C., Grose, W. L., Kasibhatla, P. S., Köhler, I., Kritz, M. A., Law, K., Penner, J. E., Ramonet, M., Reeves, C. E., Rotman, D. A., Stockwell, D. Z., Van Velthoven, P., Verver, G., Wild, O., Yang, H., and Zimmermann, P.: Evaluation and intercomparison of global atmospheric transport models using ${ }^{222} \mathrm{Rn}$ and other short-lived tracers, J. Geophys. Res., 102, 5953-5970, 1997.

Jesse, W. P.: Precision measurements of $W$ for polonium alpha par- ticles in various gases, Radiat. Res., 33, 229-237, 1968.

Jeuken, A., Siegmund, P., Heijboer, L., Feichter, J., and Bengtsson, L.: On the potential of assimilating meteorological analyses in a global climate model for the purposes of model validation, J. Geophys. Res., 101, 16939-16950, 1996.

Jin, Y., Iida, T., Wang, Z., Ikebe, Y., and Abe, S.: A subnationwide survey of outdoor and indoor ${ }^{222} \mathrm{Rn}$ concentrations in China by passive method. Radon and thoron in the human environment, in: Radon and Thorn in the Human Environment, in: Proceedings of the 7th Tohwa University International Symposium, edited by: Katase, A. and Shimo, M., World Scientific Publishing Co. Pre. Ltd., Singapore, 276-281, 1998.

Josse, B., Simon, P., and Peuch, V. H.: Radon global simulations with the multiscale chemistry and transport model MOCAGE., Tellus B, 56, 339-356, 2004.

Kazil, J., Lovejoy, E. R., Barth, M. C., and O'Brien, K.: Aerosol nucleation over oceans and the role of galactic cosmic rays, Atmos. Chem. Phys., 6, 4905-4924, doi:10.5194/acp-6-4905-2006, 2006.

Kazil, J., Stier, P., Zhang, K., Quaas, J., Kinne, S., O’Donnell, D., Rast, S., Esch, M., Ferrachat, S., Lohmann, U., and Feichter, J.: Aerosol nucleation and its role for clouds and Earth's radiative forcing in the aerosol-climate model ECHAM5-HAM, Atmos. Chem. Phys., 10, 10733-10752, doi:10.5194/acp-1010733-2010, 2010.

Koch, D., Schmidt, G. A., and Field, C. V.: Sulfur, sea salt and radionuclide aerosols in GISS ModelE, J. Geophys. Res., 111, D06206, doi:10.1029/2004JD005550, 2006.

Kulmala, M., Vehkamäki, H., Petäjä, T., Dal Maso, M., Lauri, A., Kerminen, V.-M., Birmili, W., and McMurry, P. H.: Formation and growth rates of ultrafine atmospheric particles: a review of observations, J. Aerosol Sci., 35, 143-176, 2004.

Laakso, L., Petäjä, T., Lehtinen, K. E. J., Kulmala, M., Paatero, J., Hörrak, U., Tammet, H., and Joutsensaari, J.: Ion production rate in a boreal forest based on ion, particle and radiation measurements, Atmos. Chem. Phys., 4, 1933-1943, doi:10.5194/acp-41933-2004, 2004.

Laaksonen, A., Kulmala, M., O’Dowd, C. D., Joutsensaari, J., Vaattovaara, P., Mikkonen, S., Lehtinen, K. E. J., Sogacheva, L., Dal Maso, M., Aalto, P., Petaja, T., Sogachev, A., Yoon, Y. J., Lihavainen, H., Nilsson, D., Facchini, M. C., Cavalli, F., Fuzzi, S., Hoffmann, T., Arnold, F., Hanke, M., Sellegri, K., Umann, B., Junkermann, W., Coe, H., Allan, J. D., Alfarra, M. R., Worsnop, D. R., Riekkola, M.-L., Hyotylainen, T., and Viisanen, Y.: The role of VOC oxidation products in continental new particle formation, Atmos. Chem. Phys., 8, 26572665, doi:10.5194/acp-8-2657-2008, 2008.

van der Laan, S., Neubert, R. E. M., and Meijer, H. A. J.: Methane and nitrous oxide emissions in The Netherlands: ambient measurements support the national inventories, Atmos. Chem. Phys., 9, 9369-9379, doi:10.5194/acp-9-9369-2009, 2009.

Lambert, G., Polian, G., Sanak, J., Ardouin, B., Buisson, A., Jegou, A., and Le Roulley, J. C.: Cycle du radon et de ses descendants: application à l'étude des échanges troposphèrestratosphère, Ann. Geophys., 38, 497-531, 1982, http://www.ann-geophys.net/38/497/1982/.

Lee, H. N. and Feichter, J.: An intercomparison of wet precipitation scavenging schemes and the emission rates of ${ }^{222} \mathrm{Rn}$ for the simulation of global transport and deposition of ${ }^{210} \mathrm{~Pb}$., J. Geophys. 
Res., 54, 23252-23270, 1995.

Levin, I., Born, M., Cuntz, M., Langendorfer, U., Mantsch, S., Naegler, T., Schmidt, M., Varlagin, A., Verclas, S., and Wagenbach, D.: Observations of atmospheric variability and soil exhalation rate of radon-222 at a Russian forest site. Technical approach and deployment for boundary layer studies, Tellus B, 54, 462-475, 2002.

Lin, S. J. and Rood, R. B.: Multidimensional flux-form semiLagrangian transport schemes, Mon. Weather Rev., 124, 20462070, 1996.

Lindeken, C. L.: Seasonal variations in the concentration of airborne radon and thoron daughters, Tech. Rep. USAEC Rep. UCRL-50007, University of California Lawrence Radiation Laboratory, Livermore, CA, USA, 1966.

Lockhart, L. B.: Atmospheric radioactivity in South America and Antarctica, J. Geophys. Res., 65, 3999-4005, 1960.

Lockhart, L. B.: Radioactivity of the radon-222 and radon-220 series in the air at ground level, in: The Natural Radiation Environment, edited by: Adams, J. A. and Lowder, W. M., University of Chicago Press, Chicago, USA, 331-344, 1964.

Lockhart, L. B., Patterson, R. L., and Saunders, A. W.: Airborne radioactivity in Antarctica, J. Geophys. Res., 71, 1985-1991, 1966.

Louis, J. F.: A parametric model of vertical eddy uses in the atmosphere, Bound.-Lay. Meteorol., 17, 187-202, 1979.

Lovejoy, E. R., Curtius, J., and Froyd, K. D.: Atmospheric ioninduced nucleation of sulfuric acid and water, J. Geophys. Res., 109, D08204, doi:10.1029/2003JD004460, 2004.

Lupu, A. and Cuculeanu, V.: Vertical distribution of radon progeny over vegetated ground, J. Geophys. Res., 104, 27527-27533, 1999.

Martens, C. S., Shay, T. J., Mendlovitz, H. P., Matross, D. M., Saleska, S. R., Wofsy, S. C., Stephen Woodward, W., Menton, M. C., De Moura, J. M. S., Crill, P. M., De Moraes, O. L. L., and Lima, R. L.: Radon fluxes in tropical forest ecosystems of Brazilian Amazonia: night-time $\mathrm{CO}_{2}$ net ecosystem exchange derived from radon and eddy covariance methods., Global Change Biol., 10, 618-629, 2004.

Mattsson, R.: Seasonal variation of short-lived radon progeny, $\mathrm{Pb} 210$ and $\mathrm{Po} 210$, in ground level air in Finland, J. Geophys. Res., 75, 1741-1744, 1970.

Mishra, U. C., Rangarajan, C., and Eapen, C. D.: Natural radioactivity of the atmosphere over the Indian land mass, inside deep mines, and over adjoining oceans, US Department of Energy, Washington, DC, USA, 327-346, 1980.

Nagaraja, K., Prasad, B. S. N., Madhava, M. S., Chandrashekara, M. S., Paramesh, L., Sannappa, J., Pawar, S. D., Murugavel, P., and Kamra, A. K.: Radon and its short-lived progeny: variations near the ground, Radiat. Meas., 36, 413-417, 2003.

Nordeng, T. E.: Extended versions of the convective parametrization scheme at ECMWF and their impact on the mean and transient activity of the model in the tropics, ECMWF Research Department, Technical Momorandum 206, European Centre for Medium-Range Weather Forecast, Reading, UK, 1994.

Papastefanou, C.: Radioactive Aerosols, Elsevier, Amsterdam, The Netherlands, 16-17, 2008.

Polian, G., Lambert, G., Ardouin, B., and Jegou, A.: Long-range transport of continental radon in sub-Antarctic and Antarctic areas, Tellus B, 38, 178-189, 1986.

Porstendörfer, J.: Properties and behaviour of radon and thoron and their decay products in the air, J. Aerosol Sci., 25, 219-263, 1994.

Ramamurthi, M., Strydom, R., Hopke, P. K., and Holub, R. F.: Nanometer and ultrafine aerosols from radon radiolysis, J. Aerosol Sci., 24, 393-407, 1993.

Ramonet, M., Schmidt, M., Pépin, L., Kazan, V., Picard, D., Filippi, D., Jourd'heuil, L., Valant, C., Monvoisin, G., Sarda, R., and Ciais, R.: The French Trace Gas Monitoring Program RAMCES, in: Report of the Eleventh WMO/IAEA Meeting of Experts on Carbon Dioxide Concentration and Related Tracer Measurement Techniques, edited by: Toru, S. and Kazuto, S., WMO/GAW Report 148, Tokyo, Japan, 136-148, 2003.

Rasch, P. J., Feichter, J., Law, K., Mahowald, N., Penner, J., Benkovitz, C., Genthon, C., Giannakopoulos, C., Kasibhatla, P., Koch, D., Levy, H., Maki, T., Prather, M., Roberts, D. L., Roelofs, G.-J., Stevenson, D., Stockwell, Z., Taguchi, S., Kritz, M., Chipperfield, M., Baldocchi, D., McMurry, P., Barrie, L., Balkanski, Y., Chatfield, R., Kjellstrom, E., Lawrence, M., Lee, H. N., Lelieveld, J., Noone, K. J., Seinfeld, J., Stenchikov, G., Schwartz, S., Walcek, C., and Williamson, D.: A comparison of scavenging and deposition processes in global models: results from the WCRP Cambridge Workshop of 1995, Tellus B, 52, 1025-1056, 2000.

Robertson, L. B., Stevenson, D. S., and Conen, F.: Test of a northwards-decreasing ${ }^{222} \mathrm{Rn}$ source term by comparison of modelled and observed atmospheric ${ }^{222} \mathrm{Rn}$ concentrations, Tellus B, 57, 116-123, 2005.

Roeckner, E., Bäuml, G., Bonaventura, L., Brokopf, R., Esch, M., Giorgetta, M., Hagemann, S., Kirchner, I., Kornblueh, L., Manzini, E., Rhodin, A., Schlese, U., Schulzweida, U., and Tompkins, A.: The atmospheric general circulation model ECHAM 5. PART I: model description, MPI Technical Report 349, Max Planck Institute for Meteorology, Hamburg, Germany, 2003.

Ross, J. O.: Simulation of atmospheric krypton- 85 transport to assess the detectability of clandestine nuclear reprocessing, Reports on Earth System Science 82, Max Planck Institute for Meteorology, Hamburg, 2010

Schery, D.: Progress on Global ${ }^{222}$ Rn Flux Maps and Recommendations for Future Research, in: 1st International Expert Meeting on Sources and Measurements of Natural Radionuclides Applied to Climate and Air Quality Studies (Gif-sur-Yvette, France, June 2003), edited by: Barrie, L. A. and Lee, H. N., WMO TD 1201, Gif-sur-Yvette, France, 43-47, 2004.

Schery, S. D. and Huang, S.: An estimate of the global distribution of radon emissions from the ocean, Geophys. Res. Lett., 31 L19104, doi:10.1029/2004GL021051, 2004.

Schery, S. D. and Wasiolek, M. A.: Modeling radon flux from the Earth's surface, in: Radon and Thorn in the Human Environment, in: Proceedings of the 7th Tohwa University International Symposium, edited by: Katase, A. and Shimo, M., World Scientific Publishing Co. Pre. Ltd., Singapore, 73-78, 1998.

Servant, J. and Tanaevsky, O.: Mesures de la radioactivite naturelle dans la region Parisienne, Ann. Geophys., 17, 405-409, 1961, http://www.ann-geophys.net/17/405/1961/.

Sesana, L., Ottobrini, B., Polla, G., and Facchini, U.: ${ }^{222} \mathrm{Rn}$ as indicator of atmospheric turbulence: measurements at Lake Maggiore and on the pre-Alps, J. Environ. Radioactiv., 86, 271-288, 2006. 
Stier, P., Feichter, J., Kinne, S., Kloster, S., Vignati, E., Wilson, J., Ganzeveld, L., Tegen, I., Werner, M., Balkanski, Y., Schulz, M., Boucher, O., Minikin, A., and Petzold, A.: The aerosolclimate model ECHAM5-HAM, Atmos. Chem. Phys., 5, 11251156, doi:10.5194/acp-5-1125-2005, 2005.

Sesana, L., Ottobrini, B., Polla, G., and Facchini, U.: ${ }^{222} \mathrm{Rn}$ as indicator of atmospheric turbulence: measurements at Lake Maggiore and on the pre-Alps, J. Environ. Radioactiv., 86, 271-288, 2006.

Szegvary, T.: European ${ }^{222} \mathrm{Rn}$ flux map for atmospheric tracer applications, Ph.D. thesis, Institute of Environmental Geosciences, University of Basel, Switzerland, Basel, 2007.

Szegvary, T., Leuenberger, M. C., and Conen, F.: Predicting terrestrial ${ }^{222} \mathrm{Rn}$ flux using gamma dose rate as a proxy, Atmos. Chem. Phys., 7, 2789-2795, doi:10.5194/acp-7-2789-2007, 2007.

Szegvary, T., Conen, F., and Ciais, P.: European ${ }^{222} \mathrm{Rn}$ inventory for applied atmospheric studies, Atmos. Eviron., 43, 1536-1539, 2009

Taguchi, S., Lida, T., and Moriizumi, J.: Evaluation of the atmospheric transport model NIRE-CTM-96 by using measured radon-222 concentrations, Tellus B, 54, 250-268, 2002.

Taylor, K. E., Williamson, D., and Zwiers, F.: The sea surface temperature and sea ice concentration boundary conditions for AMIP II simulations, Tech. Rep. 60, Program for Climate Model Diagnosis and Intercomparison, Lawrence Livermore National Laboratory, Livermore, USA, 2000.

Tiedtke, M.: A comprehensive mass flux scheme for cumulus parameterization in large scale models, Mon. Weather Rev., 117, 1779-1800, 1989.

Turekian, K. K., Nozaki, Y., and Benninger, L. K.: Geochemistry of atmospheric radon and radon products., Ann. Rev. Earth Planet. Sci., 5, 227-255, 1977.

Uppala, S. M., KÅllberg, P. W., Simmons, A. J., Andrae, U., Bechtold, V. D. C., Fiorino, M., Gibson, J. K., Haseler, J., Hernandez, A., Kelly, G. A., Li, X., Onogi, K., Saarinen, S., Sokka, N., Allan, R. P., Andersson, E., Arpe, K., Balmaseda, M. A., Beljaars, A. C. M., Berg, L. V. D., Bidlot, J., Bormann, N., Caires, S., Chevallier, F., Dethof, A., Dragosavac, M., Fisher, M., Fuentes, M., Hagemann, S., Hólm, E., Hoskins, B. J., Isaksen, L., Janssen, P. A. E. M., Jenne, R., McNally, A. P., Mahfouf, J.F., Morcrette, J.-J., Rayner, N. A., Saunders, R. W., Simon, P., Sterl, A., Trenberth, K. E., Untch, A., Vasiljevic, D., Viterbo, P., and Woollen, J.: The ERA-40 re-analysis, Q. J. Roy. Meteorol. Soc., 131, 2961-3012, 2005.

Valentine, J. M. and Curran, S. C.: Average energy expenditure per ion pair in gases and gas mixtures, Rep. Prog. Phys., 21, 1, 1958.

van der Laan, S., Neubert, R. E. M., and Meijer, H. A. J.: Methane and nitrous oxide emissions in The Netherlands: ambient measurements support the national inventories, Atmos. Chem. Phys., 9, 9369-9379, doi:10.5194/acp-9-9369-2009, 2009.

Vinuesa, J.-F., Basu, S., and Galmarini, S.: The diurnal evolution of ${ }^{222} \mathrm{Rn}$ and its progeny in the atmospheric boundary layer during the Wangara experiment, Atmos. Chem. Phys., 7, 5003-5019, doi:10.5194/acp-7-5003-2007, 2007.

Vohra, K. G., Subba Ramu, M. C., and Muraleedharan, T. S.: An experimental study of the role of radon and its daughters in the conversion of sulphur dioxide into aerosol particles in the atmosphere, Atmos. Environ., 18, 1653-1656, 1984.
Whittlestone, S. and Zahorowski, W.: Radon measurements at Mawson and Macquarie Island, CAASM Metadata, updated 2006, Australian Antarctic Data Centre, available online at: http: //data.aad.gov.au/aadc/portal/index.cfm?file_id=827, 2000.

Wilkening, M. H.: Daily and annual courses of natural atmospheric radioactivity., J. Geophys. Res., 64, 521-526, 1959.

Williamson, D. L.: Time-split versus process-split coupling of parameterizations and dynamical core, Mon. Weather Rev., 130, 2024-2041, 2002

Xia, Y., Sartorius, H., Schlosser, C., Stöhlker, U., Conen, F., and Zahorowski, W.: Comparison of one- and two-filter detectors for atmospheric ${ }^{222} \mathrm{Rn}$ measurements under various meteorological conditions, Atmos. Meas. Tech., 3, 723-731, doi:10.5194/amt-3723-2010, 2010.

Yu, F.: Ion-mediated nucleation in the atmosphere: key controlling parameters, implications, and look-up table, J. Geophys. Res., 115, D03206, doi:10.1029/2009JD012630, 2010.

Yu, F. and Turco, R. P.: Ultrafine aerosol formation via ionmediated nucleation, Geophys. Res. Lett., 27, 883-886, 2000.

Yu, F., Wang, Z., Luo, G., and Turco, R.: Ion-mediated nucleation as an important global source of tropospheric aerosols, Atmos. Chem. Phys., 8, 2537-2554, doi:10.5194/acp-8-2537-2008, 2008.

Yver, C., Schmidt, M., Bousquet, P., Zahorowski, W., and Ramonet, M.: Estimation of the molecular hydrogen soil uptake and traffic emissions at a suburban site near Paris through hydrogen, carbon monoxide, and radon-222 semicontinuous measurements, J. Geophys. Res., 114, D18304, doi:10.1029/2009JD012122, 2009.

Zahorowski, W. and Whittlestone, S.: Radon database 1987-1996: a review, Bureau of Meteorology and CSIRO Atmospheric Research, Melbourne, 71-80, 1999.

Zahorowski, W., Chambers, S., Wang, T., Kang, C.-H., Uno, I., Poon, S., Oh, S.-N., Werczynski, S., Kim, J., and HendersonSellers, A.: Radon-222 in boundary layer and free tropospheric continental outflow events at the three ACE-Asian sites, Tellus B, 57, 124-140, 2005.

Zellweger, C., Klausen, J., and Buchmann, B.: System and Performance Audit of Surface Ozone and Carbon Monoxide at the Global GAW Station Hohenpeissenberg, Germany., Tech. Rep. WCC-Empa Report, WMO World Calibration Centre for Surface Ozone, Carbon Monoxide and Methane, Empa Dübendorf, Switzerland, available online at: http://gaw.empa.ch/ audits/HPB_2006.pdf, 2006.

Zhang, K., Wan, H., Zhang, M., and Wang, B.: Evaluation of the atmospheric transport in a GCM using radon measurements: sensitivity to cumulus convection parameterization, Atmos. Chem. Phys., 8, 2811-2832, doi:10.5194/acp-8-2811-2008, 2008.

Zhuo, W., Guo, Q., Chen, B., and Cheng, G.: Estimating the amount and distribution of radon flux density from the soil surface in China, J. Environ. Radioactiv., 99, 1143-1148, 2008. 